\title{
2020 update on the clinical validity of cerebrospinal fluid amyloid, tau, and phospho-tau as biomarkers for Alzheimer's disease in the context of a structured 5-phase development framework
}

\author{
A. Leuzy ${ }^{1}$ • N. J. Ashton ${ }^{2,3,4} \cdot$ N. Mattsson-Carlgren ${ }^{1,5,6} \cdot$ A. Dodich ${ }^{7,8} \cdot$ M. Boccardi ${ }^{9,10} \cdot$ J. Corre $^{11} \cdot$ A. Drzezga $^{12}$.

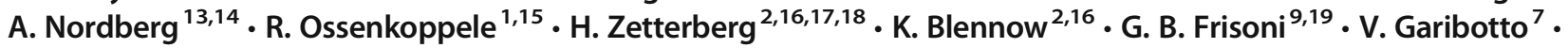 \\ O. Hansson ${ }^{1,20}$
}

Received: 12 October 2020 / Accepted: 11 February 2021 / Published online: 5 March 2021

(C) The Author(s) 2021

\begin{abstract}
Purpose In the last decade, the research community has focused on defining reliable biomarkers for the early detection of Alzheimer's disease (AD) pathology. In 2017, the Geneva AD Biomarker Roadmap Initiative adapted a framework for the systematic validation of oncological biomarkers to cerebrospinal fluid (CSF) AD biomarkers - encompassing the 42 amino-acid isoform of amyloid- $\beta$ (A $\beta 42)$, phosphorylated-tau (P-tau), and Total-tau (T-tau) — with the aim to accelerate their development and clinical implementation. The aim of this work is to update the current validation status of CSF AD biomarkers based on the Biomarker Roadmap methodology.

Methods A panel of experts in AD biomarkers convened in November 2019 at a 2-day workshop in Geneva. The level of maturity (fully achieved, partly achieved, preliminary evidence, not achieved, unsuccessful) of CSF AD biomarkers was assessed based on the Biomarker Roadmap methodology before the meeting and presented and discussed during the workshop.

Results By comparison to the previous 2017 Geneva Roadmap meeting, the primary advances in CSF AD biomarkers have been in the area of a unified protocol for CSF sampling, handling and storage, the introduction of certified reference methods and materials for $\mathrm{A} \beta 42$, and the introduction of fully automated assays. Additional advances have occurred in the form of defining thresholds for biomarker positivity and assessing the impact of covariates on their discriminatory ability.

Conclusions Though much has been achieved for phases one through three, much work remains in phases four (real world performance) and five (assessment of impact/cost). To a large degree, this will depend on the availability of disease-modifying treatments for $\mathrm{AD}$, given these will make accurate and generally available diagnostic tools key to initiate therapy.
\end{abstract}

Keywords Alzheimer's disease $\cdot \mathrm{CSF} \cdot$ strategic roadmap $\cdot \mathrm{A} \beta 42 \cdot \mathrm{P}$-tau $\cdot \mathrm{T}$-tau

\section{Introductions}

In 2017, a methodological framework for the systematic assessment of biomarker validation was imported from oncology [1] and adapted to Alzheimer's disease (AD) [2]. Within this "Biomarker Roadmap" initiative, the validation status of

This article is part of the Topical Collection on Neurology - Dementia

A. Leuzy

Antoine.Leuzy@med.lu.se

O. Hansson

Oskar.Hansson@med.lu.se

Extended author information available on the last page of the article well-consolidated biomarkers at that time [3] was assessed in the context of their use in clinical practice in patients presenting to memory clinics with mild cognitive impairment (MCI). Biomarkers included episodic memory [4], medial temporal atrophy [5], $\left[{ }^{18} \mathrm{~F}\right]$ fluoro-deoxyglucose ([ $\left.\left.{ }^{18} \mathrm{~F}\right] \mathrm{FDG}\right)$ positron emission tomography (PET) [6], Amyloid PET [7], ${ }^{123} \mathrm{I}-$ ioflupane brain single photon emission tomography, and ${ }^{123}$ I-MIBG cardiac scintigraphy [8]. Cerebrospinal fluid (CSF)-based biomarkers for AD-low levels of the 42amino acid form of $\mathrm{A} \beta(\mathrm{A} \beta 42)$ and elevated levels of phosphorylated and total tau (P-tau and T-tau, respectively) - were also reviewed (here collectively referred to as "CSF AD biomarkers") [9].

According to the previous review on CSF AD biomarkers [9], based on the evidence until 2015, these measures showed 
partial achievement of analytical and clinical validity, with large prospective real-world studies ongoing at that time. Since then, the field of CSF biomarkers has evolved significantly, especially through the introduction and extensive deployment of certified reference methods and materials for A $\beta 42$ and fully automated assays. The aim of this work is to update the current validation status of CSF AD biomarkers based on the Biomarker Roadmap methodology.

\section{Methods}

\section{Target}

This literature review investigates the validation status of CSF $\mathrm{A} \beta 42$, P-tau and T-tau as AD biomarkers, in accordance with the 2020 update (Boccardi et al., in this issue) of the Biomarker Roadmap [2,3]. The target population consists of patients with MCI referring to memory clinics due to cognitive complaints, attributed to possible sporadic and not familial dementing neurodegenerative disorders. Validation studies of CSF biomarkers were eligible for this review when including $\mathrm{AD}$ neuropathology, in vivo detection of $\mathrm{A} \beta$ deposition, or development of incidental $\mathrm{AD}$ dementia after at least 2 years of follow-up as reference standard for the biomarker-based diagnosis. Thus, eligible studies included both prospective longitudinal and cross-sectional studies.

\section{Glossary}

\section{Alzheimer's disease}

By $\mathrm{AD}$, we mean the presence of extracellular $\mathrm{A} \beta$ plaques and aggregates of hyper-phosphorylated tau in neurofibrillary tangles. These features - which typically are associated with a pattern of mediotemporal and temporoparietal neurodegenerationdefine $\mathrm{AD}$ independently of the clinical expression of cognitive symptoms [10].

\section{Alzheimer's disease dementia}

$\mathrm{AD}$ dementia denotes an acquired and progressive deterioration in memory and other cognitive functions severe enough to lead to functional impairment in activities in everyday life, according to previous criteria as defined by the National Institute of Neurological and Communicative Disorders and Stroke and the Alzheimer's disease and Related Disorders Association (NINCDS-ADRDA) criteria [11]. Notably, because of the imperfect accuracy of purely clinical criteria, a percentage of $\mathrm{AD}$ dementia cases will have non-AD pathology, or mixed AD and other types of pathology [12-14].

\section{Mild cognitive impairment}

This refers to individuals without, or with subtle, functional disability (i.e., no dementia), but with an acquired objective cognitive impairment. Representing a clinical syndrome, it encompasses cases progressing to $\mathrm{AD}$ (about $40-60 \%$ ) or non-AD dementia (about 10\%-30\%; [15-17]) as well cases who are stable during several years (about $30-50 \%$ ). MCI cases positive for $\mathrm{AD}$ biomarkers can be defined as prodromal $\mathrm{AD}$ based on research diagnostic criteria $[18,19]$. The diagnosis of $\mathrm{AD}$ at the MCI stage represents the focus of the present review.

\section{Non-Alzheimer's disease neurodegenerative disorder}

This term refers to all neurodegenerative disorders considered in the context of differential diagnosis, including progressive supranuclear palsy, corticobasal degeneration, non-fluent primary progressive aphasia, Parkinson's disease with dementia and subcortical vascular dementia.

The term is considered independent of the clinical manifestations of these diseases.

\section{Conceptual framework}

As described above, the conceptual framework for this review stems from the field of oncology [1], and has been described in detail by Boccardi et al. [2] and updated in 2020 (Boccardi et al, in this issue). Here, we summarize the application of this methodological framework to the use of CSF AD biomarkers for diagnostic purposes in routine clinical settings. Specifically, all aims are qualified as "fully achieved," "partly achieved," "preliminary evidence," or "not achieved" based on the available evidence.

\section{Phase 1}

This phase includes preclinical exploratory studies on the rationale for using CSF A $\beta 42, \mathrm{P}$-tau, and T-tau for diagnostic purposes in AD and was already fully achieved in 2017. As a result, this phase will not be covered in the present work.

\section{Phase 2}

Phase 2 studies investigate the diagnostic accuracy of CSF $\mathrm{AD}$ biomarkers to distinguish patients with $\mathrm{AD}$ dementia from cognitively unimpaired (CU) controls and subjects with nonAD dementia disorders. Phase 2 studies are meant to define the clinical assay to allow reliable assessment and identify the effect of confounders on the threshold for positivity in both patients and controls (e.g., age, gender, apolipoprotein $\varepsilon 4$ (APOE $\varepsilon 4)$ status, education or comorbidities). As the primary (discriminative accuracy between subjects with and without 
the disease) and second secondary aims (relationship between CSF measures and neuropathology) were deemed to be fully achieved in 2017, these have been omitted from the present work.

\section{Phase 3}

Phase 3 studies assess the ability of CSF AD biomarkers to detect $\mathrm{AD}$ pathology early on in the disease course (namely MCI for this specific effort) in well-controlled experimental samples. Phase 3 studies aim to define criteria for positivity, to compare the diagnostic performance with other biomarkers, and to assess the diagnostic value of combinations of biomarkers with a view to defining biomarker-based algorithms. As the primary aim of phase 3 (capacity of the biomarker to detect $\mathrm{AD}$ in subjects with $\mathrm{MCI}$, using conversion to $\mathrm{AD}$ dementia as the standard of truth-SOT) was assessed as fully achieved it 2017, it will not be covered in the present work.

\section{Phase 4}

Phase 4 studies assess the performance of CSF AD biomarkers in representative patient cohorts from memory clinics. The biomarker itself is used to support a clinical diagnosis in patients with MCI who are subsequently treated based on this CSF-supported diagnosis. They are meant to quantify the benefit of CSF-based early detection, as well as their practical feasibility and associated protocol compliance. Preliminary evidence about costs is an additional aim, in view of dedicated studies in Phase 5.

\section{Phase 5}

Phase 5 studies evaluate the impact of diagnosis based on CSF biomarkers on society (e.g., cost-effectiveness relative to clinically meaningful outcomes).

\section{Evidence assessment}

The fulfillment of each validation step from Phase 2 through 5 was assessed consistent with the approach used in the earlier 2017 Biomarker Roadmap (Boccardi et al., 2018). As such, primary and secondary aims for each phase were rated as follows: fully achieved, partly achieve, preliminary evidence, not achieved, or unsuccessful, as defined below. To facilitate the assessment and make it transparent to the readers, the data used to define the degree of fulfilment for each aim are reported and summarized in tables accessible online (see Online Resource at https://nextcloud.dzne.de/index.php/s/ so3ACxTH9n3yzdq). Adapted from a previous effort specific to AD and related disorders (Boccardi et al., 2018), these tables can facilitate formal evidence assessment [20,21].

\section{Fully achieved}

Available scientific evidence successfully replicated in properly powered and well-designed studies.

Methodologically sound and well-powered studies have provided convincing evidence that has been replicated.

\section{Partly achieved}

The available evidence is not sufficiently replicated, or samples are not adequately powered, or studies have major methodological limitations.

\section{Preliminary evidence}

Only preliminary evidence is available.

\section{Not achieved}

Studies are not yet performed at the time of the review.

\section{Unsuccessful}

Available scientific evidence shows a failure for the biomarker in achieving the aim. Findings in the subsequent roadmap phases should be interpreted with caution.

\section{Search for and selection of papers}

Phase- and aim-specific PubMed search strings are provided in Online Resource 1.

\section{Results}

Figure 1 provides an overview of the current state of CSF AD biomarkers, as per our methodological framework [1].

\section{Phase 2: Clinical assay development for AD pathology}

The overarching aim of phase 2 studies is to characterize the ability of CSF AD biomarkers to separate patients with $\mathrm{AD}$ dementia from both $\mathrm{CU}$ controls and subjects with non-AD dementia disorders.

\section{Phase 2: Secondary aim 1}

The first secondary aim of phase 2 addresses optimization of the operating procedures and assessment of the reproducibility of the assay within and between laboratories. The secondary aim 1 of phase 2 is now fully achieved for CSF A $\beta 42$, for which certified reference methods and materials for assay 


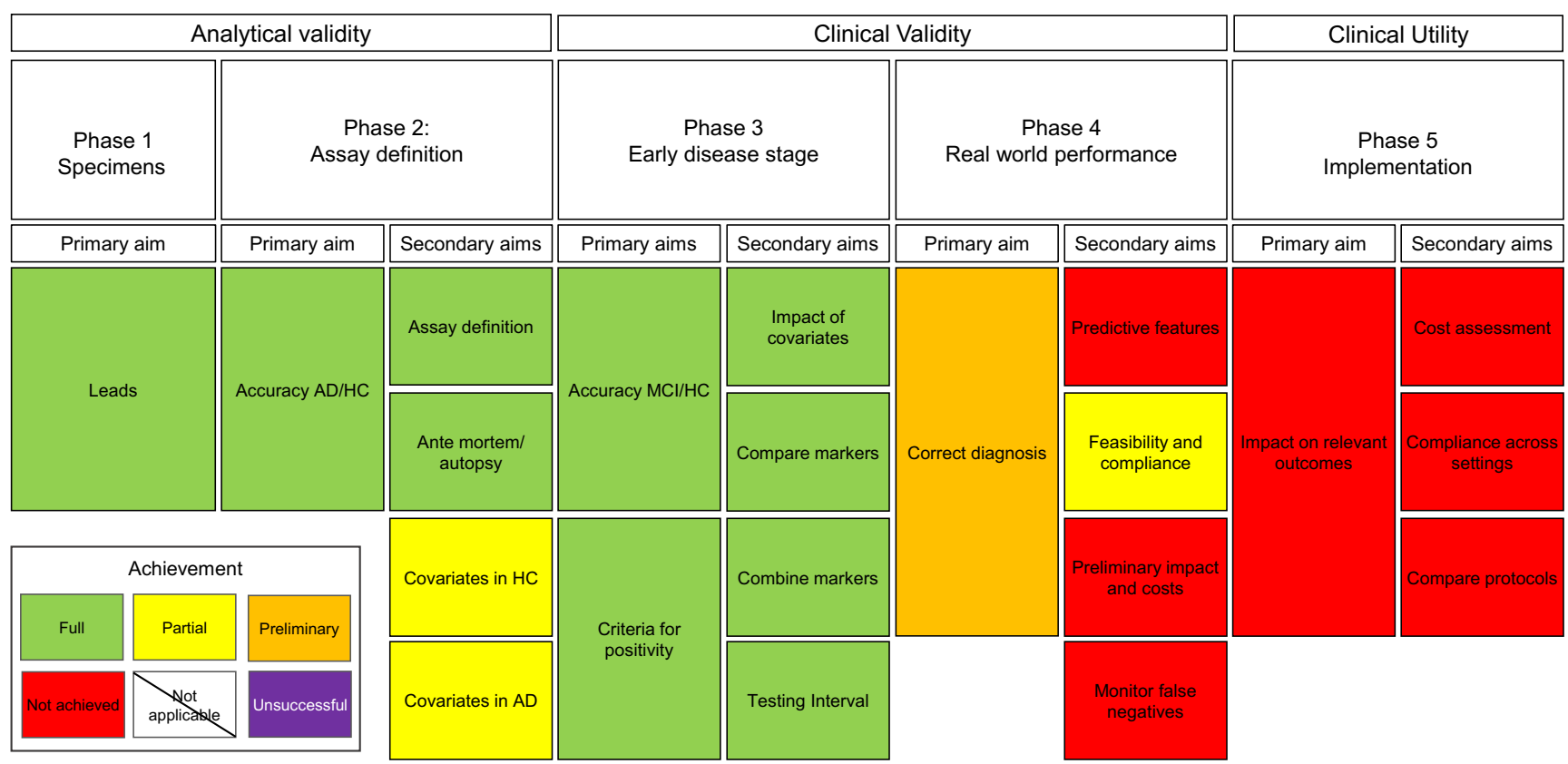

Fig. 1 A flowchart illustrating the development of CSF biomarkers for AD in the framework of Pepe et al. (2001) [1]. Abbreviations: AD, Alzheimer's disease; CSF, cerebrospinal fluid; HC, healthy controls; MCI, mild cognitive impairment

standardization are in place [22]. Similar work is ongoing but has not yet been completed for CSF tau biomarkers.

Concentrations of CSF AD biomarkers can be affected by operator-influenced preanalytical variables [23, 24], including sampling materials and methodology as well as handling and storage procedures $[23,25-32]$. The consensus within the field is that together with appropriate use criteria [33], certified reference methods and materials [22], and high precision measurements [34], the standardization of these factors will reduce variability and increase the diagnostic accuracy of these measures; this, in turn, will facilitate widespread use of CSF AD biomarkers in both clinical research and routine clinical practice $[27,35]$. Recent work addressing the influence of preanalytical factors on both CSF $A \beta 42$ and $A \beta 40$ has provided an initial protocol covering temperature and storage time, centrifugation, sample mixing, and blood contamination [35].

The most commonly used technique to measure CSF $\mathrm{AD}$ biomarkers has been the enzyme-linked immunosorbent assay (ELISA) using commercial assays [36-38]. Though reproducibility has been shown to be achievable for these measures when running analyses according to strict standard operating procedures in a single accredited laboratory [39], variability has been reported across studies [40, 41] due to preanalytical (i.e., specimen collection, shipment/storage), analytical (i.e., procedures between laboratories) and assay-related (i.e., immunoassay manufacturing procedures) factors [42]. Though a quality control (QC) program was launched by the Alzheimer's Association in 2009 in an attempt to address this, including the introduction of standard operating procedures for the ELISA methods [43], between laboratory measurement variability for CSF AD biomarkers has been consistently reported as between 15 and 25\% [44]. This persistent variability has hampered the introduction of universal biomarker cut-off values and made clear the need for more precise automated techniques.

The first publication describing the full validation and analytical performance of such an automated approach was in 2016 [45]. Using a fully automated electrochemiluminescence immunoassay (Cobas Elecsys $®$ ) for CSF A $\beta 42$, Bittner and colleagues reported repeatability coefficients of variation (CV) for human CSF pools of 1.0 to $1.6 \%$ and intermediate CVs of 1.9 to $4.0 \%$. Moreover, the assay showed very low variability between lots due to its standardisation against candidate reference materials for which the absolute concentration of $A \beta 42$ was measured using a now formally certified reference method [46]. The Elecsys ${ }^{\circledR}$ assay has now been a part of the Alzheimer's Association QC program since 2014, with mean CVs being as low as $4 \%$ as compared to $\sim 15 \%$ for ELISA methods [47]. Novel assays on the Elecsys $®$ instrument for P-tau and T-tau have also recently been described $[26,48,49]$ and have so far performed well in the Alzheimer's Association QC program [44]. Similar automated platforms for $\mathrm{AD}$ biomarkers have since been launched, including those from Euroimmun [50], and Fujirebio (LUMIPULSE®) [51-54], and have shown superior performance in the QC program [44]. The certified reference materials for $A \beta 42$ have now been fully implemented and will allow for full standardization of all commercially available CSF A $\beta 42$ methods [22]. Work to develop certified reference methods and materials for T-tau and P-tau is ongoing, under the auspices of the 
International Federation of Clinical Chemistry and Laboratory Medicine and the Global Biomarker Standardization Consortium.

\section{Phase 2: Secondary aim 3}

To assess covariates (such as gender, age, etc.) associated with biomarker status or level in control subjects. If there is an effect on the biomarker, define thresholds for positivity in each concerned subpopulation. The secondary aim 3 of phase 2 remains partially achieved.

The effect of demographic factors, such as age, sex and $A P O E \& 4$ status, on CSF AD biomarkers in $\mathrm{CU}$ individuals has been the focus of several studies. In one such study, T-tau but not $\mathrm{A} \beta 42$, has been shown to correlate positively with age in CU individuals [55]. In a related study, P-tau and T-tau, but not $\mathrm{A} \beta 42$ were also found to positively correlate with age in $\mathrm{CU}$ individuals [56]; as a result, specificities and negative predictive values in controls were found to decrease for CSF tau measures with advancing age, likely as a result of an increase in the prevalence of $A \beta$ positivity. Here, however, while the authors stressed the importance of careful characterization of control cohorts when including elderly CU individuals, they did not suggest the use of age-adjusted cutoffs for tau. Additional studies, however, have found age to be positively associated with T-tau only [57] or both tau (P-tau and Ttau) and $\mathrm{A} \beta 42[58,59]$, though only weakly for $\mathrm{A} \beta 42$.

The APOE $\varepsilon 4$ allele has been shown to be strongly linked to reduced levels of CSF A $\beta 42$ in controls [59-63]. However, CSF levels of A $\beta 42$ are not associated with APOE $\varepsilon 4$ when accounting for cortical $A \beta$ pathology (as indexed by Amyloid PET), indicating a link between CSF $A \beta 42$ and cortical $A \beta$ levels that is $A P O E \varepsilon 4$-independent, i.e., low CSF A $\beta 42$ reflects brain amyloidosis independently of $A P O E$ genotype $[64,65]$. As a result, it has been suggested that CSF A $\beta 42$ cutoffs should not be adjusted for APOE genotype [64]. Interestingly, $A P O E \varepsilon 4$ has also been shown to interact with age and gender [66], such that in $\varepsilon 4$ non-carriers, CSF A $\beta 42$ levels followed a monotonic trajectory over time for women, with men showing an increase up to midlife followed by a levelling off. Among APOE \&4 carriers, males showed a modest decline in CSF A $\beta 42$ over time, while women showed a sharper decline in $A \beta 42$, starting at around age 50 and coinciding with the onset of menopause. APOE $\varepsilon 4$ has also shown a stronger association to CSF P-tau and T-tau levels in A $\beta$ positive women compared to $\mathrm{A} \beta$-positive men [67]; this finding, combined with $A P O E \varepsilon 4$ not being differentially associated with neurofibrillary tangles at post-mortem, suggests that in the presence of $\mathrm{A} \beta$ pathology, $A P O E$ may regulate the risk for neurodegeneration in a sex-specific fashion $[68,69]$. Ageand gender-specific cutoffs have not been proposed for CSF A $\beta 42$, however.

\section{Phase 2: Secondary aim 4}

To assess covariates (e.g., gender, age, etc.) associated with biomarker status or level in diseased subjects. The secondary aim 4 of phase 2 remains partially achieved.

Older age, female sex, and $A P O E \& 4$ carriership are associated with $\mathrm{AD}$ [70]; as such, $\mathrm{CSF}$ AD-related biomarkers are more common in these groups. In patients with MCI, APOE $\varepsilon 4$ is associated with both reduced $A \beta 42[64,71]$ and increased tau levels [60,71, 72]. In APOE \&4 carriers, age is associated with lower $A \beta 42$ and higher P-tau levels [73] while female $A P O E \& 4$ carriers show a more AD-like CSF profile compared to men [74, 75]. Levels of CSF A $\beta 42$ had also been found to be significantly lower in $A P O E \& 4$ non-carriers and carriers with one $\varepsilon 4$ allele who were aged 65 and over. Agedependent increases were not observed for P-tau or T-tau; however [76]; Mofrad et al. [77] found that in female $A P O E$ $\varepsilon 4$ carriers, higher levels of CSF P-tau and T-tau were seen at the SCD and MCI stage; these differences were not seen, however, when looking at those with $\mathrm{AD}$ dementia. Among female MCI patients who were $A P O E \varepsilon 4$ non-carriers, higher P-tau and T-tau levels were seen in MCI and $\mathrm{AD}$ dementia, but not in SCD. No sex differences in A $\beta 42$ concentrations were found between females and males for any disease stage or APOE genotype. Higher levels of CSF A $\beta 42$, P-tau and Ttau have also been reported in $\mathrm{A} \beta$-positive MCI who are $A P O E$ \&4-negative, as compared to $\mathrm{A} \beta$-positive $\mathrm{MCI}$ who are $A P O E$ \&4-positive [78]. Despite these differences, however, there is as yet no evidence showing that CSF AD biomarkers are less predictive of AD pathology in any of these groups.

\section{Phase 3: Longitudinal repository studies}

The general aim of phase 3 studies is to define the ability of the biomarker to detect the disease in its early phase. For this initiative, we have chosen to focus on MCI. This phase is now largely fully achieved.

\section{Phase 3: Primary aim 2}

To define criteria for a positive biomarker test in preparation for phase 4 . The phase 3 primary aim 2 is now fully achieved for CSF A $\beta 42$, and partially achieved for P-tau and T-tau.

A variety of statistical approaches have been proposed to dichotomize continuous CSF AD biomarkers as normal or abnormal [79]. Common approaches include the maximization of accuracy for clinically diagnosed AD dementia or choosing a cut-point that yields a predefined level of sensitivity or specificity $[80,81]$. In clinical chemistry, biomarker cutoffs are commonly defined as the $95 \%$ confidence interval in people without disease. Complicating these approaches, however, is the fact that pathological brain changes can be seen 
prior to CSF AD biomarkers having become clearly abnormal [82] and clinically silent AD pathology in $\mathrm{CU}$ individuals [56]; these scenarios can lower the sensitivity and specificity of CSF AD biomarkers, respectively, at the MCI stage. Another approach, Gaussian mixture modelling, involves the use of an expectation maximization algorithm cluster individuals according to their probability of belonging to a given group (e.g., normal and abnormal CSF A $\beta 42$ ) [83]. While suitable for CSF A $\beta 42$ due its bimodal distribution this approach is less well suited to CSF tau measures due their having a more unimodal distribution. Autopsy-confirmed AD dementia cases [84] and Amyloid PET [85] have also been used to define cutoffs; both approaches, however, are not bias free (e.g., delay between CSF sampling and death, lack of CSF sample-tissue matchings from healthy controls; for PET; differences in how the data is acquired and processed and how $A \beta$ positivity thresholds are calculated [7].

Thus far, three studies have examined cutoffs for CSF A 342 and ratios with tau measurements derived using fully automated Elecsys ${ }^{\circledR}$ immunoassays [26, 86, 87]. In the study by Hansson et al. [26], cut-offs of $1100 \mathrm{pg} / \mathrm{mL}$ (Aß42), 0.022 (P-tau/A $\beta 42)$ and $0.260(\mathrm{~T}-\mathrm{tau} / \mathrm{A} \beta 42)$ were established based on concordance between CSF biomarkers and Amyloid PET in BioFINDER. When applying these predefined cutoffs to ADNI, a high concordance was observed between CSF and Amyloid PET classifications (overall percent agreement 8990\%; AUC 96\%). Using three approaches to generate cutoffs - comparison to AlzBio3, mixture modeling and concordance with Amyloid PET-Shaw et al. [86] likewise arrived at $1100 \mathrm{pg} / \mathrm{mL}$ as a cut-off for Elecsys ${ }^{\circledR} \mathrm{A} \beta 42$; similar cutoffs to those reported by Hanson et al. were also found for Ptau/A $\beta 42$ (0.023) and T-tau/A $\beta 42$ ratios (0.289). Similar cutoffs (based on Youden index for separating participants based on $\mathrm{A} \beta$-status using Amyloid PET) were also reported by Schindler et al. [87, 88] (CSF A $\beta 42,1098 \mathrm{pg} / \mathrm{mL}$; P-tau/ $\mathrm{A} \beta 42,0.0198 ; \mathrm{T}-\mathrm{tau} / \mathrm{A} \beta 42,0.211)$. In addition, the LUMIPULSE® assay, that provides a quantitative result for an analyte within $35 \mathrm{~min}$, demonstrates an $\mathrm{A} \beta 42 / \mathrm{A} \beta 40$ cutoff of 0.068 for an $\mathrm{AD}$ diagnoses but is also validated against Amyloid PET [89]. These methods are now being standardized to each other in terms of the absolute CSF A $\beta 42$ concentration they deliver [22].

\section{Phase 3: Secondary aim 1}

The secondary aim 1 of phase 3 is to explore the impact of covariates on the discriminatory abilities of the biomarker at the MCI stage. This aim is now fully achieved.

Though the specificities of individual CSF AD biomarkers have been found to decrease with age [90,91], the specificity of the three markers combined (for separating stable MCI from prodromal $\mathrm{AD}$ ) has been shown to remain essentially stable with increasing age [56]. As such, while the authors stressed the importance of careful cut-off selection, they concluded that age-adjusted cutoffs were not necessary. In a further study, motivated by findings that the diagnostic ability of $\mathrm{A} \beta 42$ could be adversely affected by the $A P O E \varepsilon 4$ allele $[9$, 60], Lautner et al. examined the association between $A P O E$ genotypes and levels of CSF A $\beta 42$, T-tau and P-tau in MCI cases that were followed longitudinally for at least 2 years [64]. The authors found that while APOE $\varepsilon 4$ was associated with lower levels of CSF A $\beta 42$, the diagnostic performance of the biomarker was independent on $A P O E$ genotype. On this basis, they concluded that the CSF A $\beta 42$ cut-offs should not be adjusted according to $A P O E$ genotype.

\section{Phase 3: Secondary aim 2}

To compare the different biomarkers available in order to select the most promising ones. The second secondary aim of phase 3 is fully achieved.

$A$ decrease in $A \beta 42$ and shorter $A \beta$ isoforms (i.e., $A \beta 40$ and $A \beta 38$ ) can be seen in non-AD dementia disorders characterized by subcortical changes (e.g., frontotemporal dementia, vascular dementia and dementia with Lewy bodies) [92-95], likely due a decline in overall $A \beta$ production levels [96] and/or neuronal activity levels [97, 98]. The use $A \beta 42 / A \beta 40$ or $A \beta 42 / A \beta 38$ ratios has been shown to increase accuracy compared to $A \beta 42$ alone for distinguishing $\mathrm{AD}$ (true $\mathrm{A} \beta 42$-positive) from such conditions, where false positives can arise if only using $A \beta 42[95,99]$.

Generally, T-tau is increased in patients with MCI who progress to $\mathrm{AD}$ dementia within a time frame of 5 years [100]. While the accuracy of P-tau is, by comparison, somewhat lower, with respect to the detection of prodromal $\mathrm{AD}$, it remains an important marker as high CSF P-tau levels are generally not found in non-AD neurodegenerative disorders [101]. Several studies, however, have shown that the combination of T-tau or P-tau with $A \beta 42$ increases the predictive power for $\mathrm{AD}$ at the MCI stage [100,102-108]. As the ratio of $\mathrm{A} \beta 42$ to $\mathrm{T}$-tau can be artificially increased via increases in $\mathrm{T}$ tau levels only, however, (e.g., due acute brain disorders such as trauma or stroke) it has been recommended that CSF AD biomarkers are to be interpreted as independent measures [9]. When applying the $\mathrm{A} \beta(\mathrm{A})$, tau $(\mathrm{T})$ and neurodegeneration (N) $(\mathrm{A} / \mathrm{T} / \mathrm{N})$ classification system using CSF AD biomarkers to extended follow-up data (up to 10 years), while the highest proportion of progression from MCI to AD dementia was seen in patients who were $\mathrm{A}+\mathrm{T}+\mathrm{N}+$, progression was also common in patients showing A-T+N+ and A-T-N- [109].

Several studies that have compared CSF AD biomarkers with amyloid and Tau PET. Concordance between CSF A $\beta 42$ and amyloid PET has been shown to be high $(\sim 90 \%)[110$, 111]; the finding that discordance is mainly seen in the form of isolated CSF A $\beta$-positivity is likely due to CSF A $\beta 42$ being a more sensitive marker of early $A \beta$ pathology [112]. Similar 
findings have been described for CSF tau [36, 113-122], including recent longitudinal work showing that CSF P-tau clearly increases before Tau PET positivity [123]. Overall, these studies suggest that CSF A $\beta 42$ and P-tau reflect the intensity of the $\mathrm{AD}$ process (stage markers) with amyloid and Tau PET, by contrast, reflecting how the density and distribution of AD pathology $[124,125]$ (i.e., how far the disease has progressed; stage marker) [114]. Only one study has to date [126], however, has examined the association between AD biomarkers and Tau PET using novel tau tracers now entering the field [127]; this study showed that while Tau PET using $\left[{ }^{18} \mathrm{~F}\right] \mathrm{RO} 948$ outperformed CSF AD biomarkers (A $\beta 42 / A \beta 40$ and $A \beta 42 / P$-tau) for separating $A D$ dementia from non-AD disorders, the reverse was seen when differentiating $\mathrm{A} \beta$-positive $\mathrm{MCI}$ from non-AD disorders [126].

Though multiple phosphorylation sites exist on the tau protein [128], the most commonly used assays for P-tau use antibodies targeting phosphorylation at threonine 181 (Ptau181) or 231 (P-tau231) [38, 129]. Though P-tau181 and 231 are strongly correlated and exhibit similar diagnostic performance [130], P-tau231 may have greater sensitivity for NFTs as it been shown to detect tau pathology in layer II of the entorhinal cortex, an area considered to be the earliest site affected by tangles in $\mathrm{AD}$ [131]. Increasing evidence indicates the presence of tau fragments spanning both the mid-domain and various terminal regions $[132,133]$. Though one such fragment, a C-terminally truncated ending at amino acid 368 (called Tau 368) was shown to be less altered in AD (including in $A \beta$-positive $C U$ ) another study however showed that the tau-368/T-tau ratio correlated with Tau PET [123]. This may reflect the deposition of Tau 368 into tangles and leaving less to be secreted to the CSF as compared to T-tau [134]. This would be in analogy with the lowering of the $A \beta 42 / 40$ ratio in patients with brain amyloidosis. In a recent study [135], tau phosphorylated at threonine 217 (P-tau217) was shown to better correlate with $\left[{ }^{18} \mathrm{~F}\right]$ flortaucipir, as compared to Ptau181, and to more accurately identify Tau PET-positive individuals. P-tau217 also better correlated with Amyloid PET and CSF A 342 and better differentiated AD dementia from non-AD disorders. Mass spectrometry-based measurements of the different tau phospho-forms corroborate these findings [136].

\section{Phase 3: Secondary aim 3}

Develop algorithms for the biomarker-based diagnosis of $\mathrm{MCI}$ in preparation of Phase-4. The third secondary aim of phase 3 is now fully achieved.

Several studies have explored whether the detection of prodromal $\mathrm{AD}$ can be improved by combining CSF AD biomarkers with cognitive tests and neuroimaging. CSF findings combined with MRI-based atrophy ratings have been shown to result in higher predictive power as compared to individual biomarkers [137, 138], with similar findings in studies that have grouped CSF with $\left[{ }^{18} \mathrm{~F}\right]$ fluorodeoxyglucose $\left(\left[{ }^{18} \mathrm{~F}\right] \mathrm{FDG}\right)$ PET $[139-141]$, and with MRI and $\left[{ }^{18} \mathrm{~F}\right] \mathrm{FDG}$ PET [142-144]. Other work has shown that while the Alzheimer's Disease Assessment Score with 13 items showed the highest effect size for differentiating stable MCI from those who progressed to AD dementia [145], risk stratification was improved by the addition of CSF P-tau. In another study, combining hippocampal volume, Functional Activities Questionnaire (FAQ) scores, and a summary measure for memory with $A P O E$ e 4 status and CSF T-tau/A $\beta 42$ ratio best predicted conversion to $\mathrm{AD}$ dementia from $\mathrm{MCI}$ over a 4-year period [146]. Similar findings were also reported by Jang et al. [147]. Other studies have reported improved predictive performance for identifying incipient $\mathrm{AD}$ by combining CSF $\mathrm{AD}$ biomarkers with neuropsychological measures [148, 149].

Two studies by van Maurik et al. addressed individualized biomarker-based risk predictions of dementia in MCI patients $[150,151]$. In a first proof-of-principal study [151], prognostic models providing probabilities of progression to $\mathrm{AD}$ dementia over the course of 1 year or 3 years were constructed based on a single-center cohort. The model combining MRI volumetric measures (hippocampal and whole-brain) and CSF (A $\beta 42$ and $\mathrm{T}$-tau) was found to provide the best prognostic value. In a follow-up multicentric study to establish the generalizability of this approach, van Maurik et al. [150] tested four separate prognostic models - including age, sex, CSF A $\beta 42$, T-tau and MMSE, as well as a model combining A/T/N biomarkers using CSF A $\beta 42$, P-tau181 and hippocampal volume. Though all models performed well, the highest performance was seen using the $\mathrm{A} / \mathrm{T} / \mathrm{N}$ based model.

\section{Phase 3: Secondary aim 4}

The secondary aim 4 of phase 3 is to determine a biomarker testing interval for phase 4 if repeated testing is of interest. Overall, there is no evidence supporting that repeated CSF measurements are needed when it comes to prediction of $\mathrm{AD}$ dementia in $\mathrm{MCI}$, as the levels of the CSF AD biomarkers seem to be stable at this stage of the disease. This aim is fully achieved.

Several cross-sectional and longitudinal studies have addressed the dynamics of CSF AD biomarkers. Using data from the Dominantly Inherited Alzheimer Network, changes in CSF A $\beta 42$ have been shown to start at least 15 years prior to expected symptom onset, with tau levels increasing 10 to 15 years before expected symptom onset (calculated as age of the participant minus parent's age at symptom onset) $[152,153]$. Despite differences in autosomal dominant and sporadic forms of $\mathrm{AD}$ - with the autosomal dominant variant associated with overproduction of $A \beta 42$ in contrast to under clearance in the sporadic form $[154,155]$ — these findings are consistent with studies in the much more common sporadic form of $\mathrm{AD}$ 
[156-160]. The study by Fagan et al. [153], however, pointed to potential reductions in CSF tau once subjects had passed their age of expected symptom onset. Additional studies in sporadic AD have reported supportive findings [161, 162]. Possibly, this may reflect a deceleration in neuronal injury or variations in the number of neurons being affected at a given disease stage [153].

At the MCI stage of $\mathrm{AD}$, longitudinal findings over the course of a nearly 10 -year period have shown that CSF levels of $\mathrm{A} \beta 42$ were decreased 5 to 10 years prior to progression to $\mathrm{AD}$ dementia, whereas T-tau and P-tau appeared to be later markers as baseline levels were significantly higher in those who converted within the first 5 years, as compared to those who converted between five and years [100]. Though longitudinal studies with serial sampling over extended periods are lacking, longitudinal findings over shorter intervals (e.g., 4 years, with CSF sampled at three time points) have shown relative stability of CSF AD biomarkers [156, 163]. These studies also provided support for the hypothesis that tau follows $A \beta$ pathology due the observation that low baseline $A \beta 42$ values were associated with longitudinal increases in P-tau, but not the opposite. In line with this, Mattsson et al. recently showed that increases in CSF P-tau181 and P-tau217 appear to follow shortly after Amyloid PET [123].

\section{Phase 4: Prospective diagnostic studies}

The general aim of phase 4 studies is to quantify the biomarker accuracy in patients diagnosed and treated based on biomarkers and perform preliminary assessment of usefulness in preparation of phase 5. Studies at this stage involve testing people and lead to diagnosis and treatment. Only preliminary evidence is available for the phase 4 aims.

\section{Phase 4: Primary aim}

To determine the operating characteristic of the biomarker in a representative population by determining the true and false positive referral rates leading toward diagnosis and treatment.

The primary aim of phase 4 is to determine the operating characteristics of the biomarker-based test in a real-world population by determining the detection and false referral rates. There is preliminary evidence for the phase 4 primary aim; longitudinal studies, however, are required for this aim to be fully achieved.

As described in the "Phase 3: Primary aim 2" section, a high $(\sim 90 \%)$ level of concordance has been reported between CSF A $\beta 42$ and Amyloid PET [110]. In a study by Palmqvist et al., CSF A $\beta 42$ and amyloid imaging using $\left[{ }^{18} \mathrm{~F}\right]$ flutemetamol PET were compared in patients with MCI from the Swedish BioFINDER study [39]. CSF A $\beta 42$, measured using consecutive samples as part of routine clinical practice by board-certified laboratory technicians at an accredited laboratory, showed high accuracy for determining cortical $\mathrm{A} \beta$ levels in MCI patients, as measured using $\left[{ }^{18} \mathrm{~F}\right]$ flutemetamol PET, with $92 \%$ of patients identically classified. Similarly, in a study by Hansson et al., CSF T-tau/A $\beta 42$ and P-tau/A $\beta 42$ ratios showed a high level of agreement with Amyloid PET based classifications in BioFINDER (90\% agreement and an AUC of 94\%) and ADNI (89\% agreement and an AUC of 96\%) [26]. Remarkably, the ratios combing $\mathrm{T}$-tau and $\mathrm{P}$-tau with $\mathrm{A} \beta 42$ were shown to be as accurate as SUVR values in predicting Amyloid PET visual reads [26].

In the few studies that have addressed concordance between CSF tau and Tau PET [113, 122], overall concordance rates have varied between approximately $50 \%$ and $70 \%$ [113]. The overall lower concordance between tau biomarkers - as compared to $A \beta[110]$ — may relate to $A \beta$ biomarkers assuming a more bimodal distribution, as compared to tau measures [113]. The discrepant concordance findings between studies likely relate to differences in the cohorts studied (in terms of age, CSF tau levels and MMSE, for instance), interval between CSF sampling and PET, the use of different Tau PET tracers, and differences in the control subjects used to define Tau PET cut-points [122].

\section{Phase 4: Secondary aim 1}

To detect the predictive features of the biomarker, considering the potential benefits due to early detection. The first secondary aim of phase 4 secondary is partially achieved.

Early diagnosis of $\mathrm{AD}$ carries a number of advantages for patients and caregivers. These include optimized medical management, future planning, participation in clinical trials, risk reduction, and reduced overall care expenditures by delaying the transition to nursing home care [164-166]. There are also ethical concerns related to disclosing a diagnosis of AD at the MCI stage [166-168], mainly tied to the fact that there are as yet no treatments able to stop or modify the course of the disease. Despite this, CSF AD biomarkers are increasingly used in clinical practice in the evaluation of MCI patients, with a survey of European Alzheimer's Disease Consortium centers [169] showing that CSF AD biomarkers were reported to be used by $22 \%$ of responders, with $79 \%$ of respondents stating that they were very to extremely comfortable giving a diagnosis of MCI due to $\mathrm{AD}$ when all three markers were abnormal.

Studies examining the impact of CSF AD biomarkers on diagnosis and diagnostic confidence have shown these measures to be of value. Kester et al. [170] showed that knowledge of CSF profiles in a non-academic memory clinic changed the diagnosis in $10 \%$ of the cases and increased diagnostic confidence in one third of cases. In a follow-up study, CSF AD biomarkers were found be to be diagnostically helpful to clinicians in $75 \%$ of cases and led to a change in diagnosis in more than $50 \%$ of MCI 
patients [171]. In a study that examined all patients visiting a tertiary center for cognitive screening during a 1year period [172], the use of CSF AD biomarkers led to a change in diagnosis in $7 \%$ of patients and a $5 \%$ increase in diagnostic confidence; CSF findings were also shown to affect clinical management (e.g., additional investigations, greater follow-up, and clinical trial selection) in $23 \%$ of patients. Similar findings were also recently described by Cognat et al. [173]. Other findings from a study that focused on the clinical utility of $\left[{ }^{18} \mathrm{~F}\right]$ flutemetamol in a tertiary memory clinic setting [174], however, showed that the primary reason $(57 \%$ of patients) for referral for Amyloid PET in MCI patients was a clinical suspicion of $\mathrm{AD}$ in the context of unclear or negative CSF findings. Furthermore, the addition of CSF A $\beta 42$, P-tau and T-tau to demographic information, neuropsychological testing, and medial temporal lobe atrophy was found to improve the accuracy of the prognosis for progression to dementia over a 5-year period in MCI patients [175].

The clinical value of CSF AD biomarkers can also be assessed indirectly. Findings from a recent a large-scale (> 16000 patients) multicentric US study (Imaging DementiaEvidence for Amyloid Scanning; IDEAS) [176] showed that knowledge of Amyloid PET status was associated with significant changes in diagnosis and patient management, including the use of drugs approved for the symptomatic treatment of $\mathrm{AD}$, other relevant drugs addressing dementia risk factors, counseling (e.g., monitoring of medications, driving and home safety), and future planning (medical/financial decision making, advanced directives). Given the high concordance between CSF $\mathrm{A} \beta 42 / 40$ or $\mathrm{A} \beta 42 / \mathrm{P}$-tau (>90\%) has with Amyloid PET [26], the clear benefits of testing for amyloid status shown by this study should also be relevant for CSF AD biomarkers.

\section{Phase 4: Secondary aim 2}

To assess the practical feasibility of implementing the biomarker-based diagnostic procedure and compliance of test-positive subjects with work-up recommendations. There is now preliminary evidence for the second secondary aim of phase 4.

Though assessing the practical feasibility of diagnostic programs and compliance of test-positive subjects with work-up and treatment recommendations may be of limited value in the absence of disease modifying treatments for $\mathrm{AD}$, several studies indicate that the clinical use of CSF AD biomarkers is feasible. The Swedish Dementia Registry [177, 178] - a national quality registry on dementia disorders used by the majority $(93 \%)$ of memory clinics in Sweden - has collected CSF AD biomarker data on a majority of patients [93, 179] and survey-based data also shows that CSF AD biomarkers are frequently used within European countries [180]. However, despite the low risk of complications [181-186], studies show that lumbar punctures (LPs) are often negatively viewed by older individuals in North America [187].

\section{Phase 4: Secondary aim 3}

The secondary aim 3 of phase 4 is to make preliminary assessments of the effects of biomarker testing on costs and burden associated with the disease. The third secondary aim of phase 4 is not achieved.

Several studies have addressed the potential economic impact of CSF AD biomarkers. Using a simulation model, Handels et al. [175] found that the use of CSF AD biomarkers in MCI patients resulted in an average gain in quality-adjusted life years of 0.046 and carried an average per patient cost of $€ 432$; this translated into an incremental cost-effectiveness ratio of $€ 9,416$. Other studies assessing the incremental cost-effectiveness of CSF AD biomarkers in a hypothetical scenario in which diseasemodifying treatments are available also support CSF measures being cost-effective [188]. Similar findings have also been reported when looking at symptomatic treatments [189]. The prevalence of AD in a given population has also been shown to affect estimates of cost-effectiveness for CSF. Lee et al. [190] found that the diagnostic use of CSF AD biomarkers is only likely to be cost-saving if the prevalence of $\mathrm{AD}$ is greater than $15 \%$ following clinical assessment and standard MRI-based neuroimaging.

Few studies have assessed whether the use of CSF AD biomarkers results in lower mortality in AD. In a study by Bruandet et al. [191], it was found that in a cohort of cognitively impaired patients $(\mathrm{AD}, \mathrm{AD}$ with cerebrovascular disease, and vascular dementia), survival was tied to the interval between initial symptoms and the first healthcare visit. As such, earlier diagnosis may reduce mortality. In patients with $\mathrm{MCI}$ due to $\mathrm{AD}$, however, it is not known whether the use of CSF AD biomarkers in routine clinical practice would reduce mortality.

\section{Phase 4: Secondary aim 4}

The secondary aim 4 of phase 4 is to monitor disease occurring clinically but not detected by the biomarker testing protocol. The fourth secondary aim of phase 4 secondary is not achieved.

Approximately 5 to $8 \%$ of patients with $\mathrm{AD}$ according to both clinical and neuropathological criteria do not have a CSF profile consistent with $\mathrm{AD}[84,192,193]$. As a result, the use of dichotomized CSF AD biomarkers to establish a diagnosis of AD would result in some false negatives. The extent of this problem, however, would also relate to the method used to set cut-offs defining what constitutes an abnormal value [189]. 


\section{Phase 5: Disease-control studies}

Studies aiming to quantify the impact of CSF AD biomarkerbased diagnosis in terms of reductions in disease-related morbidity/mortality, disability as well as the costs of biomarker testing in relation to patient costs (i.e., per life saved or quality-adjusted life year). This phase also aims to address patient compliance with screening and workup across varied settings and to compare different treatment approaches to biomarker-positive subjects and their effects on mortality and costs.

The primary aim of phase 5 is to test the capacity of a biomarker-based diagnosis to reduce the burden of AD. Secondary aims include examining patient compliance across different settings and comparing different protocols and associated benefits. As there are as yet no disease-modifying treatments for $\mathrm{AD}$, phase 5 studies have not been performed; phase 5 is therefore not achieved.

\section{Discussion}

In the present review, we aimed to update the previous work on validation status of CSF AD biomarkers [9], using a biomarker validation framework developed for oncology biomarkers [1]. Though the most important achievements, by comparison to the previous review on this topic, are the development and implementation of certified reference methods and materials for CSF A $\beta 42$, the increasing use of fully automated assays for CSF AD biomarkers and a unified protocol for how CSF samples are to be handled (phase 2, secondary aim 1), advances in the level of evidence were also found for phases 3 (primary aim 2; secondary aims 1 to 3 ) and 4 (secondary aim 2).

In comparison to the previous Roadmap meeting, the first secondary aim of phase 2-dealing with the optimization of operating procedures and assay reproducibility - is now fully achieved. As outlined by Janelidze et al. [35], there now exists a protocol for the handling of CSF AD biomarkers. Together with the appropriate use criteria for LPs [33], this protocol could serve as the basis for a universal preanalytical protocol for CSF AD biomarkers, one that could be incorporated into routine AD diagnosis and future clinical trials [27]. The Alzheimer's Associations is now leading its consensusbased approval by relevant stakeholders. The use of novel automated platforms will help provide CSF AD biomarker measurements that are both highly precise and stable; this, combined with CRMs, will facilitate the introduction of uniform cut-offs that can be applied across centers and laboratories, a key requirement for the routine use CSF AD biomarkers in memory clinics and in clinical trials with candidate diseasemodifying drugs. The availability of CSF results that are both highly precise and stable across sample batches will also facilitate the pooling of CSF AD biomarker results across research centers, allowing for studies addressing the pathogenesis and progression of $\mathrm{AD}$ and related neurodegenerative disorders. Though a mass spectrometry-based method of quantification for T-tau has been developed [194], an important and as yet unmet prerequisite for the wider use of T-tau and P-tau measurements is the current lack of CRMs for assay standardization [47]. Advances similar to those for $\mathrm{A} \beta 42$ (i.e., the development and implementation of certified reference materials and methods) $[22,195]$ will hopefully soon follow for tau [196].

In comparison to the previous Roadmap meeting, the second primary aim of phase 3-addressing the definition of criteria for biomarker positivity - is now fully achieved for CSF A 342 and partially achieved for P-tau and T-tau due the current lack of CRMs. Using the fully automated Elecsys ${ }^{\circledR}$ immunoassays, studies indicate a cut-off of $1100 \mathrm{pg} / \mathrm{mL}$ for CSF A $\beta 42[26,86,87]$ and approximately 0.02 for P-tau/A $\beta 42$ and 0.14 for T-tau/A $\beta 42$ [26, 87, 88]. A cut-off of 0.068 has also been shown for $A \beta 42 / A \beta 40$ using the LUMIPULSE $®$ assay though additional studies are required to address ratios using $A \beta 42$ and tau. With respect to the first secondary aim, which explores the impact of covariates on CSF AD biomarkers at the MCI stage, in agreement with findings from studies addressing the effects of age and APOE $[9,56,60,64,90$, 91], the Alzheimer's Biomarkers Standardization Initiative concluded that there was no need to set different cutoffs for AD CSF biomarkers based on either of these variables [197], a position also articulated in the recent recommendations for the diagnostic use of these measures in the clinical work up of patients with MCI [198].

In addition to the primary and secondary aims of phase 3 , secondary aims two and three are also now fully achieved. With respect to the second secondary aim, which aims to compare biomarkers, ratios combining $A \beta 42$ with $A \beta 40$, P-tau or $T$-tau have greater diagnostic utility compared to the use of individual CSF AD biomarkers. The superior performance of these ratios may be due to several reasons. $A \beta 42$ in ratio with $A \beta 40$ appears to compensate for between laboratory variations in the way CSF is processed $[27,199]$ and also for interindividual differences in $A \beta$ production levels $[200,201]$. The superiority of $A \beta 42$ in ratio with either P-tau or T-tau may be due to the combination of two different pathological processes into one measure [26]. In addition, these ratios may account for natural differences in the production, secretion, and breakdown of CSF proteins [202]. By comparison to PET, CSF tau measures can be described primarily as markers of disease state, with Tau PET serving as a marker of disease stage. This position is supported by a recent study that used stable isotope labeling kinetics to monitor the half-life and turnover rate of tau 
in the human CNS [203] and by recent in vivo findings $[123,126]$. Findings supportive of this model (i.e., that CSF and PET capture different aspects of AD pathology) have also been reported for $A \beta$-biomarkers $[111,112]$. Lastly, based on studies addressing the third secondary aim, which aims to developed algorithms to combine CSF AD biomarkers with other measures, multicentric data supports the combined use of CSF AD biomarkers to predict progression from MCI to $\mathrm{AD}$ dementia at the individual patient level [150]. Though the findings of this study have yet to be prospectively evaluated, it is conceivable that the models developed as part of this study could be used in clinical practice [204].

For phase 4, preliminary evidence now supports the widespread use (feasibility) of CSF AD biomarkers. This achievement rating, however, is based on European studies. In North America, many older adults have a negative perception of LPs [187] despite very limited supportive evidence [181-186]. Moreover, while it has been shown that a majority of older Americans are willing to undergo a LP for medical reasons if useful information pertaining to their health can be gained [205], enthusiasm for an LP solely for research purposes was limited. Though this finding contradicts the commonly held belief that North Americans are unwilling to undergo LPs, the authors found no modifiable factors that could improve the perception of LPs among those who view the procedure negatively [205]. Some of the perceived difficulties in performing LPs in North America, however, may relate to clinician bias, care delivery models and low reimbursement rates for LPs [206, 207]. Further studies are required to explore these issues.

Several limitations apply to this review. First, although our approach adhered to a sound methodology, rating degree of achievement for each aim should be based on a more thorough assessment of evidence, including examining various possible sources of bias (e.g., GRADE guidelines) [20]. Our online material is meant to help this development as a next step forward in a systematic assessment of the validation of $\mathrm{AD}$ biomarkers. Third, in reviewing phase 3 studies, clinical diagnosis, as opposed to post-mortem diagnosis, was used as the SOT. Lastly, though the focus of this review was the performance of CSF AD biomarkers in MCI patients, the definition of MCI was not homogeneous across studies.

\section{Conclusions}

We herein addressed the validation maturity of CSF A $\beta 42$, Ptau, and T-tau for the diagnosis of $\mathrm{AD}$ at the MCI stage. Though much has been achieved for phases one through three, much work remains to complete phases four and five, dealing with the performance of CSF AD biomarkers in representative memory clinic cohorts and health care outcomes. To a large degree, this will depend on the availability of treatments capable of modifying or stopping the course of AD.

Supplementary Information The online version contains supplementary material available at https://doi.org/10.1007/s00259-021-05258-7.

Funding Open access funding provided by Lund University. Work at the authors' research center was supported by the European Research Council, the Swedish Research Council, the Knut and Alice Wallenberg Foundation, the Marianne and Marcus Wallenberg Foundation, the Strategic Research Area MultiPark (Multidisciplinary researchin Parkinson disease) at Lund University, the Swedish Alzheimer Foundation, the Swedish Brain Foundation, the Parkinson Foundation of Sweden, the Parkinson Research Foundation, the SkåneUniversity Hospital Foundation, the Bundy Academy, and the Swedish federal government under the Agreement for Medical Education and Research.

\section{Declarations}

Ethics approval This article does not contain any studies with human participants or animals performed by any of the authors.

Conflict of interest $\mathrm{HZ}$ has served at scientific advisory boards for Denali, Roche Diagnostics, Wave, Samumed, Siemens Healthineers, Pinteon Therapeutics and $\operatorname{CogRx}$, has given lectures in symposia sponsored by Fujirebio, Alzecure and Biogen, and is a co-founder of Brain Biomarker Solutions in Gothenburg AB (BBS), which is a part of the GU Ventures Incubator Program. KB has served as a consultant, at advisory boards, or at data monitoring committees for Abcam, Axon, Biogen, JOMDD/Shimadzu. Julius Clinical, Lilly, MagQu, Novartis, Roche Diagnostics, and Siemens Healthineers, and is a co-founder of Brain Biomarker Solutions in Gothenburg AB (BBS), which is a part of the GU Ventures Incubator Program. OH has receiving grants from Roche, nonfinancial support from GE Healthcare, and grants from Biogen outside the submitted work.

$\mathrm{AL}, \mathrm{NJA}, \mathrm{NMC}, \mathrm{AD}, \mathrm{MB}, \mathrm{CJ}, \mathrm{AD}, \mathrm{AN}, \mathrm{RO}, \mathrm{GBF}$, and GB report no conflicts of interest.

Open Access This article is licensed under a Creative Commons Attribution 4.0 International License, which permits use, sharing, adaptation, distribution and reproduction in any medium or format, as long as you give appropriate credit to the original author(s) and the source, provide a link to the Creative Commons licence, and indicate if changes were made. The images or other third party material in this article are included in the article's Creative Commons licence, unless indicated otherwise in a credit line to the material. If material is not included in the article's Creative Commons licence and your intended use is not permitted by statutory regulation or exceeds the permitted use, you will need to obtain permission directly from the copyright holder. To view a copy of this licence, visit http://creativecommons.org/licenses/by/4.0/.

\section{References}

1. Pepe MS, Etzioni R, Feng Z, Potter JD, Thompson ML, Thornquist $\mathrm{M}$, et al. Phases of biomarker development for early 
detection of cancer. J Natl Cancer Inst. 2001;93:1054-61. https:// doi.org/10.1093/jnci/93.14.1054.

2. Boccardi M, Gallo V, Yasui Y, Vineis P, Padovani A, Mosimann $\mathrm{U}$, et al. The biomarker-based diagnosis of Alzheimer's disease. 2lessons from oncology. Neurobiol Aging. 2017;52:141-52. https://doi.org/10.1016/j.neurobiolaging.2017.01.021.

3. Frisoni GB, Perani D, Bastianello S, Bernardi G, Porteri C, Boccardi M, et al. Biomarkers for the diagnosis of Alzheimer's disease in clinical practice: an Italian intersocietal roadmap. Neurobiol Aging. 2017;52:119-31. https://doi.org/10.1016/j. neurobiolaging.2016.02.033.

4. Cerami C, Dubois B, Boccardi M, Monsch AU, Demonet JF, Cappa SF, et al. Clinical validity of delayed recall tests as a gateway biomarker for Alzheimer's disease in the context of a structured 5-phase development framework. Neurobiol Aging. 2017;52:153-66. https://doi.org/10.1016/j.neurobiolaging.2016. 03.034 .

5. Ten Kate M, Barkhof F, Boccardi M, Visser PJ, Jack CR Jr, Lovblad KO, et al. Clinical validity of medial temporal atrophy as a biomarker for Alzheimer's disease in the context of a structured 5-phase development framework. Neurobiol Aging. 2017;52:167-82 e1. https://doi.org/10.1016/j.neurobiolaging. 2016.05.024.

6. Garibotto V, Herholz K, Boccardi M, Picco A, Varrone A, Nordberg A, et al. Clinical validity of brain fluorodeoxyglucose positron emission tomography as a biomarker for Alzheimer's disease in the context of a structured 5-phase development framework. Neurobiol Aging. 2017;52:183-95. https://doi.org/10. 1016/j.neurobiolaging.2016.03.033.

7. Chiotis K, Saint-Aubert L, Boccardi M, Gietl A, Picco A, Varrone A, et al. Clinical validity of increased cortical uptake of amyloid ligands on PET as a biomarker for Alzheimer's disease in the context of a structured 5-phase development framework. Neurobiol Aging. 2017;52:214-27. https://doi.org/10.1016/j. neurobiolaging.2016.07.012.

8. Sonni I, Ratib O, Boccardi M, Picco A, Herholz K, Nobili F, et al. Clinical validity of presynaptic dopaminergic imaging with (123)I-ioflupane and noradrenergic imaging with (123)I-MIBG in the differential diagnosis between Alzheimer's disease and dementia with Lewy bodies in the context of a structured 5-phase development framework. Neurobiol Aging. 2017;52:228-42. https://doi.org/10.1016/j.neurobiolaging.2016.04.026.

9. Mattsson N, Lonneborg A, Boccardi M, Blennow K, Hansson O. Geneva Task Force for the Roadmap of Alzheimer's B. Clinical validity of cerebrospinal fluid Abeta42, tau, and phospho-tau as biomarkers for Alzheimer's disease in the context of a structured 5phase development framework. Neurobiol Aging. 2017;52:196213. https://doi.org/10.1016/j.neurobiolaging.2016.02.034.

10. Jack CR Jr, Bennett DA, Blennow K, Carrillo MC, Dunn B, Haeberlein SB, et al. NIA-AA Research Framework: toward a biological definition of Alzheimer's disease. Alzheimers Dement. 2018;14:535-62. https://doi.org/10.1016/j.jalz.2018.02.018.

11. McKhann G, Drachman D, Folstein M, Katzman R, Price D, Stadlan EM. Clinical diagnosis of Alzheimer's disease: report of the NINCDS-ADRDA Work Group under the auspices of Department of Health and Human Services Task Force on Alzheimer's Disease. Neurology. 1984;34:939-44. https://doi. org/10.1212/wnl.34.7.939.

12. Beach TG, Monsell SE, Phillips LE, Kukull W. Accuracy of the clinical diagnosis of Alzheimer disease at National Institute on Aging Alzheimer Disease Centers, 2005-2010. J Neuropathol Exp Neurol. 2012;71:266-73. https://doi.org/10.1097/NEN. 0b013e31824b211b.

13. James BD, Wilson RS, Boyle PA, Trojanowski JQ, Bennett DA, Schneider JA. TDP-43 stage, mixed pathologies, and clinical
Alzheimer's-type dementia. Brain. 2016;139:2983-93. https:// doi.org/10.1093/brain/aww224.

14. Kovacs GG, Milenkovic I, Wohrer A, Hoftberger R, Gelpi E, Haberler C, et al. Non-Alzheimer neurodegenerative pathologies and their combinations are more frequent than commonly believed in the elderly brain: a community-based autopsy series. Acta Neuropathol. 2013;126:365-84. https://doi.org/10.1007/s00401013-1157-y.

15. Bennett DA, Wilson RS, Schneider JA, Evans DA, Beckett LA, Aggarwal NT, et al. Natural history of mild cognitive impairment in older persons. Neurology. 2002;59:198-205. https://doi.org/10. 1212/wnl.59.2.198.

16. Jack CR Jr, Lowe VJ, Senjem ML, Weigand SD, Kemp BJ, Shiung MM, et al. 11C PiB and structural MRI provide complementary information in imaging of Alzheimer's disease and amnestic mild cognitive impairment. Brain. 2008;131:665-80. https://doi.org/10.1093/brain/awm336.

17. Rowe CC, Ellis KA, Rimajova M, Bourgeat P, Pike KE, Jones G, et al. Amyloid imaging results from the Australian Imaging, Biomarkers and Lifestyle (AIBL) study of aging. Neurobiol Aging. 2010;31:1275-83. https://doi.org/10.1016/j. neurobiolaging.2010.04.007.

18. Dubois B, Feldman HH, Jacova C, Hampel H, Molinuevo JL, Blennow K, et al. Advancing research diagnostic criteria for Alzheimer's disease: the IWG-2 criteria. Lancet Neurol. 2014;13:614-29. https://doi.org/10.1016/S1474-4422(14)700900 .

19. Albert MS, DeKosky ST, Dickson D, Dubois B, Feldman HH, Fox NC, et al. The diagnosis of mild cognitive impairment due to Alzheimer's disease: recommendations from the National Institute on Aging-Alzheimer's Association workgroups on diagnostic guidelines for Alzheimer's disease. Alzheimers Dement. 2011;7: 270-9. https://doi.org/10.1016/j.jalz.2011.03.008.

20. Guyatt G, Oxman AD, Akl EA, Kunz R, Vist G, Brozek J, et al. GRADE guidelines: 1. Introduction-GRADE evidence profiles and summary of findings tables. J Clin Epidemiol. 2011;64:38394. https://doi.org/10.1016/j.jclinepi.2010.04.026.

21. Guyatt GH, Oxman AD, Vist G, Kunz R, Brozek J, Alonso-Coello P, et al. GRADE guidelines: 4. Rating the quality of evidencestudy limitations (risk of bias). J Clin Epidemiol. 2011;64:407-15. https://doi.org/10.1016/j.jclinepi.2010.07.017.

22. Boulo S, Kuhlmann J, Andreasson U, Brix B, Venkataraman I, Herbst V, et al. First amyloid beta1-42 certified reference material for re-calibrating commercial immunoassays. Alzheimers Dement. 2020. https://doi.org/10.1002/alz.12145.

23. Vanderstichele H, Bibl M, Engelborghs S, Le Bastard N, Lewczuk $\mathrm{P}$, Molinuevo JL, et al. Standardization of preanalytical aspects of cerebrospinal fluid biomarker testing for Alzheimer's disease diagnosis: a consensus paper from the Alzheimer's Biomarkers Standardization Initiative. Alzheimers Dement. 2012;8:65-73. https://doi.org/10.1016/j.jalz.2011.07.004.

24. Willemse E, van Uffelen K, Brix B, Engelborghs S, Vanderstichele H, Teunissen C. How to handle adsorption of cerebrospinal fluid amyloid beta (1-42) in laboratory practice? Identifying problematic handlings and resolving the issue by use of the Abeta42/Abeta40 ratio. Alzheimers Dement. 2017;13:885-92. https://doi.org/10.1016/j.jalz.2017.01.010.

25. del Campo M, Mollenhauer B, Bertolotto A, Engelborghs S, Hampel H, Simonsen AH, et al. Recommendations to standardize preanalytical confounding factors in Alzheimer's and Parkinson's disease cerebrospinal fluid biomarkers: an update. Biomark Med. 2012;6:419-30. https://doi.org/10.2217/bmm.12.46.

26. Hansson O, Seibyl J, Stomrud E, Zetterberg H, Trojanowski JQ, Bittner T, et al. CSF biomarkers of Alzheimer's disease concord with amyloid-beta PET and predict clinical progression: a study of fully automated immunoassays in BioFINDER and ADNI 
cohorts. Alzheimers Dement. 2018;14:1470-81. https://doi.org/ 10.1016/j.jalz.2018.01.010.

27. Hansson O, Mikulskis A, Fagan AM, Teunissen C, Zetterberg H, Vanderstichele $\mathrm{H}$, et al. The impact of preanalytical variables on measuring cerebrospinal fluid biomarkers for Alzheimer's disease diagnosis: A review. Alzheimers Dement. 2018;14:1313-33. https://doi.org/10.1016/j.jalz.2018.05.008.

28. Toombs J, Foiani MS, Wellington H, Paterson RW, Arber C, Heslegrave A, et al. Amyloid beta peptides are differentially vulnerable to preanalytical surface exposure, an effect incompletely mitigated by the use of ratios. Alzheimers Dement (Amst). 2018;10:311-21. https://doi.org/10.1016/j.dadm.2018.02.005.

29. Vanderstichele HM, Janelidze S, Demeyer L, Coart E, Stoops E, Herbst V, et al. Optimized standard operating procedures for the analysis of cerebrospinal fluid Abeta42 and the ratios of Abeta isoforms using low protein binding tubes. J Alzheimers Dis. 2016;53:1121-32. https://doi.org/10.3233/JAD-160286.

30. Rozga M, Bittner T, Hoglund K, Blennow K. Accuracy of cerebrospinal fluid Abeta1-42 measurements: evaluation of preanalytical factors using a novel Elecsys immunosassay. Clin Chem Lab Med. 2017;55:1545-54. https://doi.org/10.1515/cclm2016-1061.

31. Willemse EAJ, van Uffelen KWJ, van der Flier WM, Teunissen CE. Effect of long-term storage in biobanks on cerebrospinal fluid biomarker Abeta1-42, T-tau, and P-tau values. Alzheimers Dement (Amst). 2017;8:45-50. https://doi.org/10.1016/j.dadm. 2017.03.005.

32. Lewczuk P, Gaignaux A, Kofanova O, Ermann N, Betsou F, Brandner $\mathrm{S}$, et al. Interlaboratory proficiency processing scheme in CSF aliquoting: implementation and assessment based on biomarkers of Alzheimer's disease. Alzheimers Res Ther. 2018;10: 87. https://doi.org/10.1186/s13195-018-0418-3.

33. Shaw LM, Arias J, Blennow K, Galasko D, Molinuevo JL, Salloway S, et al. Appropriate use criteria for lumbar puncture and cerebrospinal fluid testing in the diagnosis of Alzheimer's disease. Alzheimers Dement. 2018;14:1505-21. https://doi.org/ 10.1016/j.jalz.2018.07.220.

34. Blennow K, Zetterberg H. Fluid biomarker-based molecular phenotyping of Alzheimer's disease patients in research and clinical settings. Prog Mol Biol Transl Sci. 2019;168:3-23. https://doi.org/ 10.1016/bs.pmbts.2019.07.006.

35. Janelidze S, Stomrud E, Brix B, Hansson O. Towards a unified protocol for handling of CSF before beta-amyloid measurements. Alzheimers Res Ther. 2019;11:63. https://doi.org/10.1186/ s13195-019-0517-9.

36. Andreasen N, Minthon L, Clarberg A, Davidsson P, Gottfries J, Vanmechelen E, et al. Sensitivity, specificity, and stability of CSFtau in $\mathrm{AD}$ in a community-based patient sample. Neurology. 1999;53:1488-94. https://doi.org/10.1212/wnl.53.7.1488.

37. Blennow K, Wallin A, Agren H, Spenger C, Siegfried J, Vanmechelen E. Tau protein in cerebrospinal fluid: a biochemical marker for axonal degeneration in Alzheimer disease? Mol Chem Neuropathol. 1995;26:231-45. https://doi.org/10.1007/ BF02815140.

38. Vanmechelen E, Vanderstichele H, Davidsson P, Van Kerschaver E, Van Der Perre B, Sjogren M, et al. Quantification of tau phosphorylated at threonine 181 in human cerebrospinal fluid: a sandwich ELISA with a synthetic phosphopeptide for standardization. Neurosci Lett. 2000;285:49-52. https://doi.org/10.1016/s03043940(00)01036-3.

39. Palmqvist S, Zetterberg H, Blennow K, Vestberg S, Andreasson U, Brooks DJ, et al. Accuracy of brain amyloid detection in clinical practice using cerebrospinal fluid beta-amyloid 42: a crossvalidation study against amyloid positron emission tomography. JAMA Neurol. 2014;71:1282-9. https://doi.org/10.1001/ jamaneurol.2014.1358.
40. Sunderland T, Linker G, Mirza N, Putnam KT, Friedman DL, Kimmel LH, et al. Decreased beta-amyloid1-42 and increased tau levels in cerebrospinal fluid of patients with Alzheimer disease. JAMA. 2003;289:2094-103. https://doi.org/10.1001/jama. 289.16.2094.

41. Mattsson N, Andreasson U, Persson S, Arai H, Batish SD, Bernardini S, et al. The Alzheimer's Association external quality control program for cerebrospinal fluid biomarkers. Alzheimers Dement. 2011;7:386-95 e6. https://doi.org/10.1016/j.jalz.2011. 05.2243 .

42. Jicha GA, Lane E, Vincent I, Otvos L Jr, Hoffmann R, Davies P. A conformation- and phosphorylation-dependent antibody recognizing the paired helical filaments of Alzheimer's disease. J Neurochem. 1997;69:2087-95. https://doi.org/10.1046/j.14714159.1997.69052087.x.

43. Mattsson N, Andreasson U, Persson S, Carrillo MC, Collins S, Chalbot S, et al. CSF biomarker variability in the Alzheimer's Association quality control program. Alzheimers Dement. 2013;9:251-61. https://doi.org/10.1016/j.jalz.2013.01.010.

44. Blennow K, Zetterberg H. Biomarkers for Alzheimer's disease: current status and prospects for the future. J Intern Med. 2018;284:643-63. https://doi.org/10.1111/joim.12816.

45. Bittner T, Zetterberg H, Teunissen CE, Ostlund RE Jr, Militello $\mathrm{M}$, Andreasson U, et al. Technical performance of a novel, fully automated electrochemiluminescence immunoassay for the quantitation of beta-amyloid (1-42) in human cerebrospinal fluid. Alzheimers Dement. 2016;12:517-26. https://doi.org/10.1016/j. jalz.2015.09.009.

46. Leinenbach A, Pannee J, Dulffer T, Huber A, Bittner T, Andreasson U, et al. Mass spectrometry-based candidate reference measurement procedure for quantification of amyloid-beta in cerebrospinal fluid. Clin Chem. 2014;60:987-94. https://doi. org/10.1373/clinchem.2013.220392.

47. Blennow K, Zetterberg H. The past and the future of Alzheimer's disease fluid biomarkers. J Alzheimers Dis. 2018;62:1125-40. https://doi.org/10.3233/JAD-170773.

48. Lifke V, Kollmorgen G, Manuilova E, Oelschlaegel T, Hillringhaus L, Widmann M, et al. Elecsys $((\mathrm{R}))$ Total-Tau and Phospho-Tau (181P) CSF assays: analytical performance of the novel, fully automated immunoassays for quantification of tau proteins in human cerebrospinal fluid. Clin Biochem. 2019;72: 30-8. https://doi.org/10.1016/j.clinbiochem.2019.05.005.

49. Blennow K, Shaw LM, Stomrud E, Mattsson N, Toledo JB, Buck $\mathrm{K}$, et al. Predicting clinical decline and conversion to Alzheimer's disease or dementia using novel Elecsys Abeta(1-42), pTau and tTau CSF immunoassays. Sci Rep. 2019;9:19024. https://doi.org/ 10.1038/s41598-019-54204-z.

50. Chiasserini D, Biscetti L, Farotti L, Eusebi P, Salvadori N, Lisetti $\mathrm{V}$, et al. Performance evaluation of an automated ELISA system for Alzheimer's disease detection in clinical routine. J Alzheimers Dis. 2016;54:55-67. https://doi.org/10.3233/JAD-160298.

51. Bayart JL, Hanseeuw B, Ivanoiu A, van Pesch V. Analytical and clinical performances of the automated Lumipulse cerebrospinal fluid Abeta42 and T-Tau assays for Alzheimer's disease diagnosis. J Neurol. 2019;266:2304-11. https://doi.org/10.1007/s00415019-09418-6.

52. Zecca C, Brescia V, Piccininni M, Capozzo R, Barone R, Barulli $\mathrm{MR}$, et al. Comparative evaluation of two immunoassays for cerebrospinal fluid beta-Amyloid1-42 measurement. Clin Chim Acta. 2019;493:107-11. https://doi.org/10.1016/j.cca.2019.02. 033.

53. Leitao MJ, Silva-Spinola A, Santana I, Olmedo V, Nadal A, Le Bastard N, et al. Clinical validation of the Lumipulse G cerebrospinal fluid assays for routine diagnosis of Alzheimer's disease. Alzheimers Res Ther. 2019;11:91. https://doi.org/10.1186/ s13195-019-0550-8. 
54. Kollhoff AL, Howell JC, Hu WT. Automation vs. Experience: Measuring Alzheimer's Beta-Amyloid 1-42 Peptide in the CSF. Front Aging Neurosci. 2018;10:253. https://doi.org/10.3389/ fnagi.2018.00253.

55. Sjogren M, Vanderstichele H, Agren H, Zachrisson O, Edsbagge M, Wikkelso C, et al. Tau and Abeta42 in cerebrospinal fluid from healthy adults 21-93 years of age: establishment of reference values. Clin Chem. 2001;47:1776-81.

56. Mattsson N, Rosen E, Hansson O, Andreasen N, Parnetti L, Jonsson M, et al. Age and diagnostic performance of Alzheimer disease CSF biomarkers. Neurology. 2012;78:468-76. https://doi. org/10.1212/WNL.0b013e3182477eed.

57. Bussy A, Snider BJ, Coble D, Xiong C, Fagan AM, Cruchaga C, et al. Effect of apolipoprotein E4 on clinical, neuroimaging, and biomarker measures in noncarrier participants in the Dominantly Inherited Alzheimer Network. Neurobiol Aging. 2019;75:42-50. https://doi.org/10.1016/j.neurobiolaging.2018.10.011.

58. Toledo JB, Zetterberg H, van Harten AC, Glodzik L, MartinezLage P, Bocchio-Chiavetto L, et al. Alzheimer's disease cerebrospinal fluid biomarker in cognitively normal subjects. Brain. 2015;138:2701-15. https://doi.org/10.1093/brain/awv199.

59. Peskind ER, Li G, Shofer J, Quinn JF, Kaye JA, Clark CM, et al. Age and apolipoprotein $\mathrm{E}^{*} 4$ allele effects on cerebrospinal fluid beta-amyloid 42 in adults with normal cognition. Arch Neurol. 2006;63:936-9. https://doi.org/10.1001/archneur.63.7.936.

60. Vemuri P, Wiste HJ, Weigand SD, Knopman DS, Shaw LM, Trojanowski JQ, et al. Effect of apolipoprotein E on biomarkers of amyloid load and neuronal pathology in Alzheimer disease. Ann Neurol. 2010;67:308-16. https://doi.org/10.1002/ana.21953.

61. Sunderland T, Mirza N, Putnam KT, Linker G, Bhupali D, Durham R, et al. Cerebrospinal fluid beta-amyloid1-42 and tau in control subjects at risk for Alzheimer's disease: the effect of APOE epsilon4 allele. Biol Psychiatry. 2004;56:670-6. https:// doi.org/10.1016/j.biopsych.2004.07.021.

62. Sutphen CL, Jasielec MS, Shah AR, Macy EM, Xiong C, Vlassenko AG, et al. Longitudinal cerebrospinal fluid biomarker changes in preclinical Alzheimer disease during middle age. JAMA Neurol. 2015;72:1029-42. https://doi.org/10.1001/ jamaneurol.2015.1285.

63. Prince JA, Zetterberg H, Andreasen N, Marcusson J, Blennow K. APOE epsilon4 allele is associated with reduced cerebrospinal fluid levels of Abeta42. Neurology. 2004;62:2116-8. https://doi. org/10.1212/01.wnl.0000128088.08695.05.

64. Lautner R, Palmqvist S, Mattsson N, Andreasson U, Wallin A, Palsson E, et al. Apolipoprotein E genotype and the diagnostic accuracy of cerebrospinal fluid biomarkers for Alzheimer disease. JAMA Psychiatry. 2014;71:1183-91. https://doi.org/10.1001/ jamapsychiatry.2014.1060.

65. Morris JC, Roe CM, Xiong C, Fagan AM, Goate AM, Holtzman DM, et al. APOE predicts amyloid-beta but not tau Alzheimer pathology in cognitively normal aging. Ann Neurol. 2010;67: 122-31. https://doi.org/10.1002/ana.21843.

66. Li G, Shofer JB, Petrie EC, Yu CE, Wilkinson CW, Figlewicz DP, et al. Cerebrospinal fluid biomarkers for Alzheimer's and vascular disease vary by age, gender, and APOE genotype in cognitively normal adults. Alzheimers Res Ther. 2017;9:48. https://doi.org/ 10.1186/s13195-017-0271-9.

67. Hohman TJ, Dumitrescu L, Barnes LL, Thambisetty M, Beecham G, Kunkle B, et al. Sex-specific association of apolipoprotein E with cerebrospinal fluid levels of Tau. JAMA Neurol. 2018;75: 989-98. https://doi.org/10.1001/jamaneurol.2018.0821.

68. Koran MEI, Wagener M, Hohman TJ, Alzheimer's NI. Sex differences in the association between $\mathrm{AD}$ biomarkers and cognitive decline. Brain Imaging Behav. 2017;11:205-13. https://doi.org/ 10.1007/s11682-016-9523-8.
69. Buckley RF, Mormino EC, Chhatwal J, Schultz AP, Rabin JS, Rentz DM, et al. Associations between baseline amyloid, sex, and APOE on subsequent tau accumulation in cerebrospinal fluid. Neurobiol Aging. 2019;78:178-85. https://doi.org/10.1016/j. neurobiolaging.2019.02.019.

70. Gamache J, Yun Y, Chiba-Falek O. Sex-dependent effect of APOE on Alzheimer's disease and other age-related neurodegenerative disorders. Dis Model Mech. 2020;13. https://doi.org/10. 1242/dmm.045211.

71. Risacher SL, Kim S, Shen L, Nho K, Foroud T, Green RC, et al. The role of apolipoprotein E (APOE) genotype in early mild cognitive impairment (E-MCI). Front Aging Neurosci. 2013;5:11. https://doi.org/10.3389/fnagi.2013.00011.

72. Marizzoni M, Ferrari C, Babiloni C, Albani D, Barkhof F, Cavaliere L, et al. CSF cutoffs for MCI due to AD depend on APOEepsilon4 carrier status. Neurobiol Aging. 2020;89:55-62. https://doi.org/10.1016/j.neurobiolaging.2019.12.019.

73. Kester MI, Blankenstein MA, Bouwman FH, van Elk EJ, Scheltens P, van der Flier WM. CSF biomarkers in Alzheimer's disease and controls: associations with APOE genotype are modified by age. J Alzheimers Dis. 2009;16:601-7. https://doi.org/10. 3233/JAD-2009-0999.

74. Altmann A, Tian L, Henderson VW, Greicius MD, Alzheimer's Disease Neuroimaging Initiative I. Sex modifies the APOE-related risk of developing Alzheimer disease. Ann Neurol. 2014;75:563573. doi:https://doi.org/10.1002/ana.24135.

75. Holland D, Desikan RS, Dale AM, McEvoy LK. Alzheimer's Disease Neuroimaging I. Higher rates of decline for women and apolipoprotein E epsilon4 carriers. AJNR Am J Neuroradiol. 2013;34:2287-93. https://doi.org/10.3174/ajnr.A3601.

76. Knapskog AB, Eldholm RS, Braekhus A, Engedal K, Saltvedt I. Factors that influence the levels of cerebrospinal fluid biomarkers in memory clinic patients. BMC Geriatr. 2017;17:210. https://doi. org/10.1186/s12877-017-0611-4.

77. Mofrad RB, Tijms BM, Scheltens P, Barkhof F, van der Flier WM, Am Sikkes S, et al. Sex differences in CSF biomarkers vary by Alzheimer's disease stage and APOE epsilon4 genotype. Neurology. 2020. https://doi.org/10.1212/WNL. 0000000000010629.

78. Mattsson N, Eriksson O, Lindberg O, Scholl M, Lampinen B, Nilsson M, et al. Effects of APOE epsilon4 on neuroimaging, cerebrospinal fluid biomarkers, and cognition in prodromal Alzheimer's disease. Neurobiol Aging. 2018;71:81-90. https:// doi.org/10.1016/j.neurobiolaging.2018.07.003.

79. Bartlett JW, Frost C, Mattsson N, Skillback T, Blennow K, Zetterberg $\mathrm{H}$, et al. Determining cut-points for Alzheimer's disease biomarkers: statistical issues, methods and challenges. Biomark Med. 2012;6:391-400. https://doi.org/10.2217/bmm.12.49.

80. Alvarez I, Aguilar M, Gonzalez JM, Ysamat M, Lorenzo-Bosquet C, Alonso A, et al. Clinic-based validation of cerebrospinal fluid biomarkers with florbetapir PET for diagnosis of dementia. $\mathrm{J}$ Alzheimers Dis. 2018;61:135-43. https://doi.org/10.3233/JAD170753.

81. Muller EG, Edwin TH, Stokke C, Navelsaker SS, Babovic A, Bogdanovic N, et al. Amyloid-beta PET-Correlation with cerebrospinal fluid biomarkers and prediction of Alzheimer s disease diagnosis in a memory clinic. PLoS One. 2019;14:e0221365. https://doi.org/10.1371/journal.pone.0221365.

82. Insel PS, Mattsson N, Donohue MC, Mackin RS, Aisen PS, Jack $\mathrm{CR} \mathrm{Jr}$, et al. The transitional association between beta-amyloid pathology and regional brain atrophy. Alzheimers Dement. 2015;11:1171-9. https://doi.org/10.1016/j.jalz.2014.11.002.

83. Bertens D, Tijms BM, Scheltens P, Teunissen CE, Visser PJ. Unbiased estimates of cerebrospinal fluid beta-amyloid 1-42 cutoffs in a large memory clinic population. Alzheimers Res Ther. 2017;9:8. https://doi.org/10.1186/s13195-016-0233-7. 
84. Shaw LM, Vanderstichele H, Knapik-Czajka M, Clark CM, Aisen PS, Petersen RC, et al. Cerebrospinal fluid biomarker signature in Alzheimer's disease neuroimaging initiative subjects. Ann Neurol. 2009;65:403-13. https://doi.org/10.1002/ana.21610.

85. Zwan MD, Rinne JO, Hasselbalch SG, Nordberg A, Lleo A, Herukka SK, et al. Use of amyloid-PET to determine cutpoints for CSF markers: a multicenter study. Neurology. 2016;86:50-8. https://doi.org/10.1212/WNL.0000000000002081.

86. Shaw LM, Waligorska T, Fields L, Korecka M, Figurski M, Trojanowski JQ, et al. Derivation of cutoffs for the Elecsys $((\mathrm{R}))$ amyloid beta (1-42) assay in Alzheimer's disease. Alzheimers Dement (Amst). 2018;10:698-705. https://doi.org/10.1016/j. dadm.2018.07.002.

87. Schindler SE, Gray JD, Gordon BA, Xiong C, Batrla-Utermann R, Quan M, et al. Cerebrospinal fluid biomarkers measured by Elecsys assays compared to amyloid imaging. Alzheimers Dement. 2018;14:1460-9. https://doi.org/10.1016/j.jalz.2018.01. 013.

88. Schneider JA, Arvanitakis Z, Leurgans SE, Bennett DA. The neuropathology of probable Alzheimer disease and mild cognitive impairment. Ann Neurol. 2009;66:200-8. https://doi.org/10. 1002/ana.21706.

89. Therriault J, Benedet A, Pascoal TA, Savard M, Ashton N, Chamoun $\mathrm{M}$, et al. Determining amyloid-beta positivity using [(18)F]AZD4694 PET imaging. J Nucl Med. 2020. https://doi. org/10.2967/jnumed.120.245209.

90. Visser PJ, Verhey F, Knol DL, Scheltens P, Wahlund LO, FreundLevi Y, et al. Prevalence and prognostic value of CSF markers of Alzheimer's disease pathology in patients with subjective cognitive impairment or mild cognitive impairment in the DESCRIPA study: a prospective cohort study. Lancet Neurol. 2009;8:619-27. https://doi.org/10.1016/S1474-4422(09)70139-5.

91. De Meyer G, Shapiro F, Vanderstichele H, Vanmechelen E, Engelborghs S, De Deyn PP, et al. Diagnosis-independent Alzheimer disease biomarker signature in cognitively normal elderly people. Arch Neurol. 2010;67:949-56. https://doi.org/10. 1001/archneurol.2010.179.

92. Ewers M, Mattsson N, Minthon L, Molinuevo JL, Antonell A, Popp J, et al. CSF biomarkers for the differential diagnosis of Alzheimer's disease: a large-scale international multicenter study. Alzheimers Dement. 2015;11:1306-15. https://doi.org/10.1016/j. jalz.2014.12.006.

93. Skillback T, Farahmand BY, Rosen C, Mattsson N, Nagga K, Kilander L, et al. Cerebrospinal fluid tau and amyloid-beta1-42 in patients with dementia. Brain. 2015;138:2716-31. https://doi. org/10.1093/brain/awv181.

94. Janelidze S, Stomrud E, Palmqvist S, Zetterberg H, van Westen D, Jeromin A, et al. Plasma beta-amyloid in Alzheimer's disease and vascular disease. Sci Rep. 2016;6:26801. https://doi.org/10.1038/ srep26801.

95. van Westen D, Lindqvist D, Blennow K, Minthon L, Nagga K, Stomrud E, et al. Cerebral white matter lesions - associations with Abeta isoforms and amyloid PET. Sci Rep. 2016;6:20709. https:// doi.org/10.1038/srep20709.

96. Selnes P, Blennow K, Zetterberg H, Grambaite R, Rosengren L, Johnsen L, et al. Effects of cerebrovascular disease on amyloid precursor protein metabolites in cerebrospinal fluid. Cerebrospinal Fluid Res. 2010;7:10. https://oi.org/10.1186/1743-8454-7-10.

97. Ballard C, O'Brien J, Gray A, Cormack F, Ayre G, Rowan E, et al. Attention and fluctuating attention in patients with dementia with Lewy bodies and Alzheimer disease. Arch Neurol. 2001;58:97782. https://doi.org/10.1001/archneur.58.6.977.

98. Kamenetz F, Tomita T, Hsieh H, Seabrook G, Borchelt D, Iwatsubo $\mathrm{T}$, et al. APP processing and synaptic function. Neuron. 2003;37:925-37. https://doi.org/10.1016/s08966273(03)00124-7.
99. Janelidze S, Zetterberg H, Mattsson N, Palmqvist S, Vanderstichele H, Lindberg O, et al. CSF Abeta42/Abeta40 and Abeta42/Abeta38 ratios: better diagnostic markers of Alzheimer disease. Ann Clin Transl Neurol. 2016;3:154-65. https://doi.org/ 10.1002/acn3.274.

100. Buchhave P, Minthon L, Zetterberg H, Wallin AK, Blennow K, Hansson O. Cerebrospinal fluid levels of beta-amyloid 1-42, but not of tau, are fully changed already 5 to 10 years before the onset of Alzheimer dementia. Arch Gen Psychiatry. 2012;69:98-106. https://doi.org/10.1001/archgenpsychiatry.2011.155.

101. Blennow K. Cerebrospinal fluid protein biomarkers for Alzheimer's disease. NeuroRx. 2004;1:213-25. https://doi.org/ 10.1602/neurorx.1.2.213.

102. Parnetti L, Chiasserini D, Eusebi P, Giannandrea D, Bellomo G, De Carlo C, et al. Performance of abeta1-40, abeta1-42, total tau, and phosphorylated tau as predictors of dementia in a cohort of patients with mild cognitive impairment. J Alzheimers Dis. 2012;29:229-38. https://doi.org/10.3233/JAD-2011-111349.

103. Duits FH, Teunissen CE, Bouwman FH, Visser PJ, Mattsson N, Zetterberg $\mathrm{H}$, et al. The cerebrospinal fluid "Alzheimer profile": easily said, but what does it mean? Alzheimers Dement. 2014;10: 713-23 e2. https://doi.org/10.1016/j.jalz.2013.12.023.

104. Gaser C, Franke K, Kloppel S, Koutsouleris N, Sauer H. Alzheimer's disease neuroimaging I. BrainAGE in mild cognitive impaired patients: predicting the conversion to Alzheimer's disease. PLoS One. 2013;8:e67346. https://doi.org/10.1371/journal. pone. 0067346 .

105. Hertze J, Minthon L, Zetterberg H, Vanmechelen E, Blennow K, Hansson O. Evaluation of CSF biomarkers as predictors of Alzheimer's disease: a clinical follow-up study of 4.7 years. J Alzheimers Dis. 2010;21:1119-28. https://doi.org/10.3233/jad2010-100207.

106. Landau SM, Harvey D, Madison CM, Reiman EM, Foster NL, Aisen PS, et al. Comparing predictors of conversion and decline in mild cognitive impairment. Neurology. 2010;75:230-8. https:// doi.org/10.1212/WNL.0b013e3181e8e8b8.

107. Vos S, van Rossum I, Burns L, Knol D, Scheltens P, Soininen H, et al. Test sequence of CSF and MRI biomarkers for prediction of AD in subjects with MCI. Neurobiol Aging. 2012;33:2272-81. https://doi.org/10.1016/j.neurobiolaging.2011.12.017.

108. Blanco-Canto ME, Monge-Argiles JA, Perez-Cejuela C, Badia C, Gabaldon L, Munoz-Ruiz C, et al. Diagnostic validity comparison between criteria based on CSF Alzheimer's disease biomarkers. Am J Alzheimers Dis Other Demen. 2017;32:101-7. https://doi. org $/ 10.1177 / 1533317516688298$.

109. Grontvedt GR, Lauridsen C, Berge G, White LR, Salvesen O, Brathen $\mathrm{G}$, et al. The amyloid, tau, and neurodegeneration (A/T/ N) classification applied to a clinical research cohort with longterm follow-up. J Alzheimers Dis. 2020;74:829-37. https://doi. org/10.3233/JAD-191227.

110. Blennow K, Mattsson N, Scholl M, Hansson O, Zetterberg H. Amyloid biomarkers in Alzheimer's disease. Trends Pharmacol Sci. 2015;36:297-309. https://doi.org/10.1016/j.tips.2015.03.002.

111. Mattsson N, Insel PS, Donohue M, Landau S, Jagust WJ, Shaw $\mathrm{LM}$, et al. Independent information from cerebrospinal fluid amyloid-beta and florbetapir imaging in Alzheimer's disease. Brain. 2015;138:772-83. https://doi.org/10.1093/brain/awu367.

112. Palmqvist S, Mattsson N, Hansson O. Alzheimer's Disease Neuroimaging I. Cerebrospinal fluid analysis detects cerebral amyloid-beta accumulation earlier than positron emission tomography. Brain. 2016;139:1226-36. https://doi.org/10.1093/brain/ aww015.

113. Mattsson N, Scholl M, Strandberg O, Smith R, Palmqvist S, Insel PS, et al. (18)F-AV-1451 and CSF T-tau and P-tau as biomarkers in Alzheimer's disease. EMBO Mol Med. 2017;9:1212-23. https://doi.org/10.15252/emmm.201707809. 
114. Blennow K, Hampel H. CSF markers for incipient Alzheimer's disease. Lancet Neurol. 2003;2:605-13. https://doi.org/10.1016/ s1474-4422(03)00530-1.

115. Wolters EE, Ossenkoppele R, Verfaillie SCJ, Coomans EM, Timmers T, Visser D, et al. Regional [(18)F]flortaucipir PET is more closely associated with disease severity than CSF p-tau in Alzheimer's disease. Eur J Nucl Med Mol Imaging. 2020. https:// doi.org/10.1007/s00259-020-04758-2.

116. Mattsson N, Smith R, Strandberg O, Palmqvist S, Scholl M, Insel PS, et al. Comparing (18)F-AV-1451 with CSF t-tau and p-tau for diagnosis of Alzheimer disease. Neurology. 2018;90:e388-e95. https://doi.org/10.1212/WNL.0000000000004887.

117. Zetterberg H, Pedersen M, Lind K, Svensson M, Rolstad S, Eckerstrom C, et al. Intra-individual stability of CSF biomarkers for Alzheimer's disease over two years. J Alzheimers Dis. 2007;12:255-60. https://doi.org/10.3233/jad-2007-12307.

118. Blennow K, Zetterberg H, Minthon L, Lannfelt L, Strid S, Annas $\mathrm{P}$, et al. Longitudinal stability of CSF biomarkers in Alzheimer's disease. Neurosci Lett. 2007;419:18-22. https://doi.org/10.1016/j. neulet.2007.03.064.

119. Brier MR, Gordon B, Friedrichsen K, McCarthy J, Stern A, Christensen J, et al. Tau and Abeta imaging, CSF measures, and cognition in Alzheimer's disease. Sci Transl Med. 2016;8:338-66. https://doi.org/10.1126/scitranslmed.aaf2362.

120. Chhatwal JP, Schultz AP, Marshall GA, Boot B, Gomez-Isla T, Dumurgier J, et al. Temporal T807 binding correlates with CSF tau and phospho-tau in normal elderly. Neurology. 2016;87:920 6. https://doi.org/10.1212/WNL.0000000000003050.

121. Gordon BA, Friedrichsen K, Brier M, Blazey T, Su Y, Christensen $\mathrm{J}$, et al. The relationship between cerebrospinal fluid markers of Alzheimer pathology and positron emission tomography tau imaging. Brain. 2016;139:2249-60. https://doi.org/10.1093/brain/ aww139.

122. Leuzy A, Cicognola C, Chiotis K, Saint-Aubert L, Lemoine L, Andreasen N, et al. Longitudinal tau and metabolic PET imaging in relation to novel CSF tau measures in Alzheimer's disease. Eur J Nucl Med Mol Imaging. 2019;46:1152-63. https://doi.org/10. 1007/s00259-018-4242-6.

123. Mattsson-Carlgren N, Andersson E, Janelidze S, Ossenkoppele R, Insel $\mathrm{P}$, Strandberg $\mathrm{O}$, et al. Abeta deposition is associated with increases in soluble and phosphorylated tau that precede a positive Tau PET in Alzheimer's disease. Sci Adv. 2020;6:eaaz2387. https://doi.org/10.1126/sciadv.aaz2387.

124. Fleisher AS, Pontecorvo MJ, Devous MD Sr, Lu M, Arora AK, Truocchio SP, et al. Positron emission tomography imaging with $[18 \mathrm{~F}]$ flortaucipir and postmortem assessment of Alzheimer disease neuropathologic changes. JAMA Neurol. 2020. https://doi. org/10.1001/jamaneurol.2020.0528.

125. Jack CR Jr, Barrio JR, Kepe V. Cerebral amyloid PET imaging in Alzheimer's disease. Acta Neuropathol. 2013;126:643-57. https:// doi.org/10.1007/s00401-013-1185-7.

126. Leuzy A, Smith R, Ossenkoppele R, Santillo A, Borroni E, Klein G, et al. Diagnostic performance of RO948 F 18 tau positron emission tomography in the differentiation of Alzheimer disease from other neurodegenerative disorders. JAMA Neurol. 2020. https://doi.org/10.1001/jamaneurol.2020.0989.

127. Leuzy A, Chiotis K, Lemoine L, Gillberg PG, Almkvist O, Rodriguez-Vieitez E, et al. Tau PET imaging in neurodegenerative tauopathies-still a challenge. Mol Psychiatry. 2019;24:111234. https://doi.org/10.1038/s41380-018-0342-8.

128. Portelius E, Hansson SF, Tran AJ, Zetterberg H, Grognet P, Vanmechelen E, et al. Characterization of tau in cerebrospinal fluid using mass spectrometry. J Proteome Res. 2008;7:2114 20. https://doi.org/10.1021/pr7008669.

129. Kohnken R, Buerger K, Zinkowski R, Miller C, Kerkman D, DeBernardis J, et al. Detection of tau phosphorylated at threonine
231 in cerebrospinal fluid of Alzheimer's disease patients. Neurosci Lett. 2000;287:187-90. https://doi.org/10.1016/s03043940(00)01178-2.

130. Hampel H, Buerger K, Zinkowski R, Teipel SJ, Goernitz A, Andreasen N, et al. Measurement of phosphorylated tau epitopes in the differential diagnosis of Alzheimer disease: a comparative cerebrospinal fluid study. Arch Gen Psychiatry. 2004;61:95-102. https://doi.org/10.1001/archpsyc.61.1.95.

131. Vincent I, Zheng JH, Dickson DW, Kress Y, Davies P. Mitotic phosphoepitopes precede paired helical filaments in Alzheimer's disease. Neurobiol Aging. 1998;19:287-96. https://doi.org/10. 1016/s0197-4580(98)00071-2.

132. Meredith JE Jr, Sankaranarayanan S, Guss V, Lanzetti AJ, Berisha F, Neely RJ, et al. Characterization of novel CSF Tau and ptau biomarkers for Alzheimer's disease. PLoS One. 2013;8:e76523. https://doi.org/10.1371/journal.pone.0076523.

133. Cicognola C, Brinkmalm G, Wahlgren J, Portelius E, Gobom J, Cullen NC, et al. Novel tau fragments in cerebrospinal fluid: relation to tangle pathology and cognitive decline in Alzheimer's disease. Acta Neuropathol. 2019;137:279-96. https://doi.org/10. 1007/s00401-018-1948-2.

134. Blennow K, Chen C, Cicognola C, Wildsmith KR, Manser PT, Bohorquez SMS, et al. Cerebrospinal fluid tau fragment correlates with tau PET: a candidate biomarker for tangle pathology. Brain. 2020;143:650-60. https://doi.org/10.1093/brain/awz346.

135. Janelidze S, Stomrud E, Smith R, Palmqvist S, Mattsson N, Airey DC, et al. Cerebrospinal fluid p-tau217 performs better than $\mathrm{p}$ tau181 as a biomarker of Alzheimer's disease. Nat Commun. 2020;11:1683. https://doi.org/10.1038/s41467-020-15436-0.

136. Barthelemy NR, Bateman RJ, Hirtz C, Marin P, Becher F, Sato C, et al. Cerebrospinal fluid phospho-tau T217 outperforms T181 as a biomarker for the differential diagnosis of Alzheimer's disease and PET amyloid-positive patient identification. Alzheimers Res Ther. 2020;12:26. https://doi.org/10.1186/s13195-020-00596-4.

137. Vemuri P, Wiste HJ, Weigand SD, Shaw LM, Trojanowski JQ, Weiner MW, et al. MRI and CSF biomarkers in normal, MCI, and AD subjects: predicting future clinical change. Neurology. 2009;73:294-301. https://doi.org/10.1212/WNL. 0b013e3181af79fb.

138. Bouwman FH, Schoonenboom SN, van der Flier WM, van Elk EJ, Kok A, Barkhof F, et al. CSF biomarkers and medial temporal lobe atrophy predict dementia in mild cognitive impairment. Neurobiol Aging. 2007;28:1070-4. https://doi.org/10.1016/j. neurobiolaging.2006.05.006.

139. Fellgiebel A, Scheurich A, Bartenstein P, Muller MJ. FDG-PET and CSF phospho-tau for prediction of cognitive decline in mild cognitive impairment. Psychiatry Res. 2007;155:167-71. https:// doi.org/10.1016/j.pscychresns.2006.12.002.

140. Caminiti SP, Ballarini T, Sala A, Cerami C, Presotto L, Santangelo $\mathrm{R}$, et al. FDG-PET and CSF biomarker accuracy in prediction of conversion to different dementias in a large multicentre MCI cohort. Neuroimage Clin. 2018;18:167-77. https://doi.org/10.1016/ j.nicl.2018.01.019.

141. Santangelo R, Masserini F, Agosta F, Sala A, Caminiti SP, Cecchetti G, et al. CSF p-tau/Abeta42 ratio and brain FDG-PET may reliably detect MCI "imminent" converters to AD. Eur J Nucl Med Mol Imaging. 2020. https://doi.org/10.1007/s00259-02004853-4

142. Walhovd KB, Fjell AM, Brewer J, McEvoy LK, FennemaNotestine C, Hagler DJ Jr, et al. Combining MR imaging, positron-emission tomography, and CSF biomarkers in the diagnosis and prognosis of Alzheimer disease. AJNR Am J Neuroradiol. 2010;31:347-54. https://doi.org/10.3174/ajnr. A1809.

143. Zhang D, Wang Y, Zhou L, Yuan H, Shen D. Alzheimer's Disease Neuroimaging I. Multimodal classification of Alzheimer's disease 
and mild cognitive impairment. Neuroimage. 2011;55:856-67. https://doi.org/10.1016/j.neuroimage.2011.01.008.

144. Ottoy J, Niemantsverdriet E, Verhaeghe J, De Roeck E, Struyfs H, Somers C, et al. Association of short-term cognitive decline and MCI-to-AD dementia conversion with CSF, MRI, amyloid- and (18)F-FDG-PET imaging. Neuroimage Clin. 2019;22:101771. https://doi.org/10.1016/j.nicl.2019.101771.

145. Lange C, Suppa P, Pietrzyk U, Makowski MR, Spies L, Peters O, et al. Prediction of Alzheimer's Dementia in Patients with Amnestic Mild Cognitive Impairment in Clinical Routine: Incremental Value of Biomarkers of Neurodegeneration and Brain Amyloidosis Added Stepwise to Cognitive Status. J Alzheimers Dis. 2018;61:373-88. https://doi.org/10.3233/JAD170705 .

146. Steenland K, Zhao L, John SE, Goldstein FC, Levey A, Alvaro A, et al. A 'Framingham-like' algorithm for predicting 4-year risk of progression to amnestic mild cognitive impairment or Alzheimer's disease using multidomain information. J Alzheimers Dis. 2018;63:1383-93. https://doi.org/10.3233/JAD-170769.

147. Jang H, Park J, Woo S, Kim S, Kim HJ, Na DL, et al. Prediction of fast decline in amyloid positive mild cognitive impairment patients using multimodal biomarkers. Neuroimage Clin. 2019;24: 101941. https://doi.org/10.1016/j.nicl.2019.101941.

148. Mazzeo S, Santangelo R, Bernasconi MP, Cecchetti G, Fiorino A, Pinto P, et al. Combining cerebrospinal fluid biomarkers and neuropsychological assessment: a simple and cost-effective algorithm to predict the progression from mild cognitive impairment to Alzheimer's disease dementia. J Alzheimers Dis. 2016;54:1495508. https://doi.org/10.3233/JAD-160360.

149. Rosenberg A, Solomon A, Jelic V, Hagman G, Bogdanovic N, Kivipelto M. Progression to dementia in memory clinic patients with mild cognitive impairment and normal beta-amyloid. Alzheimers Res Ther. 2019;11:99. https://doi.org/10.1186/ s13195-019-0557-1.

150. van Maurik IS, Vos SJ, Bos I, Bouwman FH, Teunissen CE, Scheltens P, et al. Biomarker-based prognosis for people with mild cognitive impairment (ABIDE): a modelling study. Lancet Neurol. 2019;18:1034-44. https://doi.org/10.1016/S14744422(19)30283-2.

151. van Maurik IS, Zwan MD, Tijms BM, Bouwman FH, Teunissen $\mathrm{CE}$, Scheltens $\mathrm{P}$, et al. Interpreting biomarker results in individual patients with mild cognitive impairment in the Alzheimer's biomarkers in Daily Practice (ABIDE) Project. JAMA Neurol. 2017;74:1481-91. https://doi.org/10.1001/jamaneurol.2017.2712.

152. Bateman RJ, Xiong C, Benzinger TL, Fagan AM, Goate A, Fox $\mathrm{NC}$, et al. Clinical and biomarker changes in dominantly inherited Alzheimer's disease. N Engl J Med. 2012;367:795-804. https:// doi.org/10.1056/NEJMoa1202753.

153. Fagan AM, Xiong C, Jasielec MS, Bateman RJ, Goate AM, Benzinger TL, et al. Longitudinal change in CSF biomarkers in autosomal-dominant Alzheimer's disease. Sci Transl Med. 2014;6:226ra30. doi:10.1126/scitranslmed.3007901.

154. Mawuenyega KG, Sigurdson W, Ovod V, Munsell L, Kasten T, Morris JC, et al. Decreased clearance of CNS beta-amyloid in Alzheimer's disease. Science. 2010;330:1774. https://doi.org/10. 1126/science.1197623.

155. Scheuner D, Eckman C, Jensen M, Song X, Citron M, Suzuki N, et al. Secreted amyloid beta-protein similar to that in the senile plaques of Alzheimer's disease is increased in vivo by the presenilin 1 and 2 and APP mutations linked to familial Alzheimer's disease. Nat Med. 1996;2:864-70. https://doi.org/ 10.1038/nm0896-864.

156. Toledo JB, Xie SX, Trojanowski JQ, Shaw LM. Longitudinal change in CSF Tau and Abeta biomarkers for up to 48 months in ADNI. Acta Neuropathol. 2013;126:659-70. https://doi.org/10. 1007/s00401-013-1151-4.
157. Villemagne VL, Burnham S, Bourgeat P, Brown B, Ellis KA, Salvado O, et al. Amyloid beta deposition, neurodegeneration, and cognitive decline in sporadic Alzheimer's disease: a prospective cohort study. Lancet Neurol. 2013;12:357-67. https://doi.org/ 10.1016/S1474-4422(13)70044-9.

158. Sperling RA, Aisen PS, Beckett LA, Bennett DA, Craft S, Fagan AM, et al. Toward defining the preclinical stages of Alzheimer's disease: recommendations from the National Institute on AgingAlzheimer's Association workgroups on diagnostic guidelines for Alzheimer's disease. Alzheimers Dement. 2011;7:280-92. https:// doi.org/10.1016/j.jalz.2011.03.003.

159. Jack CR Jr, Knopman DS, Jagust WJ, Shaw LM, Aisen PS, Weiner MW, et al. Hypothetical model of dynamic biomarkers of the Alzheimer's pathological cascade. Lancet Neurol. 2010;9: 119-28. https://doi.org/10.1016/S1474-4422(09)70299-6.

160. Jack CR Jr, Vemuri P, Wiste HJ, Weigand SD, Aisen PS, Trojanowski JQ, et al. Evidence for ordering of Alzheimer disease biomarkers. Arch Neurol. 2011;68:1526-35. https://doi.org/10. 1001/archneurol.2011.183.

161. Sutphen CL, McCue L, Herries EM, Xiong C, Ladenson JH, Holtzman DM, et al. Longitudinal decreases in multiple cerebrospinal fluid biomarkers of neuronal injury in symptomatic late onset Alzheimer's disease. Alzheimers Dement. 2018;14:869 79. https://doi.org/10.1016/j.jalz.2018.01.012.

162. Lleo A, Alcolea D, Martinez-Lage P, Scheltens P, Parnetti L, Poirier J, et al. Longitudinal cerebrospinal fluid biomarker trajectories along the Alzheimer's disease continuum in the BIOMARKAPD study. Alzheimers Dement. 2019;15:742-53. https://doi.org/10.1016/j.jalz.2019.01.015.

163. Mattsson N, Portelius E, Rolstad S, Gustavsson M, Andreasson U, Stridsberg M, et al. Longitudinal cerebrospinal fluid biomarkers over four years in mild cognitive impairment. J Alzheimers Dis. 2012;30:767-78. https://doi.org/10.3233/JAD-2012-120019.

164. Banerjee S, Wittenberg R. Clinical and cost effectiveness of services for early diagnosis and intervention in dementia. Int J Geriatr Psychiatry. 2009;24:748-54. https://doi.org/10.1002/gps.2191.

165. Relkin N. Screening and early diagnosis of dementia. Am J Manag Care. 2000;6:S1111-8 discussion S9-24.

166. Gauthier S, Leuzy A, Racine E, Rosa-Neto P. Diagnosis and management of Alzheimer's disease: past, present and future ethical issues. Prog Neurobiol. 2013;110:102-13. https://doi.org/10. 1016/j.pneurobio.2013.01.003.

167. Mattsson N, Brax D, Zetterberg H. To know or not to know: ethical issues related to early diagnosis of Alzheimer's disease. Int J Alzheimers Dis. 2010;2010. https://doi.org/10.4061/2010/ 841941.

168. Gauthier S, Leuzy A. Diagnosis of prodromal Alzheimer's disease: do you really want to know? Can J Neurol Sci. 2010;37:2. https:// doi.org/10.1017/s0317167100009574.

169. Bocchetta M, Galluzzi S, Kehoe PG, Aguera E, Bernabei R, Bullock R, et al. The use of biomarkers for the etiologic diagnosis of MCI in Europe: an EADC survey. Alzheimers Dement. 2015;11:195-206 e1. https://doi.org/10.1016/j.jalz.2014.06.006.

170. Kester MI, Boelaarts L, Bouwman FH, Vogels RL, Groot ER, van Elk EJ, et al. Diagnostic impact of CSF biomarkers in a local hospital memory clinic. Dement Geriatr Cogn Disord. 2010;29: 491-7. https://doi.org/10.1159/000313534.

171. Boelaarts L, de Jonghe JFM, Scheltens P. Diagnostic impact of CSF biomarkers in a local hospital memory clinic revisited. Dement Geriatr Cogn Disord. 2020:1-6. https://doi.org/10.1159/ 000506332.

172. Duits FH, Prins ND, Lemstra AW, Pijnenburg YA, Bouwman FH, Teunissen CE, et al. Diagnostic impact of CSF biomarkers for Alzheimer's disease in a tertiary memory clinic. Alzheimers Dement. 2015;11:523-32. https://doi.org/10.1016/j.jalz.2014.05. 1753. 
173. Cognat E, Mouton Liger F, Troussiere AC, Wallon D, Dumurgier $\mathrm{J}$, Magnin E, et al. What is the clinical impact of cerebrospinal fluid biomarkers on final diagnosis and management in patients with mild cognitive impairment in clinical practice? Results from a nation-wide prospective survey in France. BMJ Open. 2019;9: e026380. https://doi.org/10.1136/bmjopen-2018-026380.

174. Leuzy A, Savitcheva I, Chiotis K, Lilja J, Andersen P, Bogdanovic $\mathrm{N}$, et al. Clinical impact of [(18)F]flutemetamol PET among memory clinic patients with an unclear diagnosis. Eur J Nucl Med Mol Imaging. 2019;46:1276-86. https://doi.org/10.1007/s00259-01904297-5.

175. Handels RLH, Wimo A, Dodel R, Kramberger MG, Visser PJ, Molinuevo JL, et al. Cost-utility of using Alzheimer's disease biomarkers in cerebrospinal fluid to predict progression from mild cognitive impairment to dementia. J Alzheimers Dis. 2017;60: 1477-87. https://doi.org/10.3233/JAD-170324.

176. Rabinovici GD, Gatsonis C, Apgar C, Chaudhary K, Gareen I, Hanna L, et al. Association of amyloid positron emission tomography with subsequent change in clinical management among medicare beneficiaries with mild cognitive impairment or dementia. JAMA. 2019;321:1286-94. https://doi.org/10.1001/jama. 2019.2000.

177. Wimo A, Religa D, Spangberg K, Edlund AK, Winblad B, Eriksdotter M. Costs of diagnosing dementia: results from SveDem, the Swedish Dementia Registry. Int J Geriatr Psychiatry. 2013;28:1039-44. https://doi.org/10.1002/gps.3925.

178. Religa D, Spangberg K, Wimo A, Edlund AK, Winblad B, Eriksdotter-Jonhagen M. Dementia diagnosis differs in men and women and depends on age and dementia severity: data from SveDem, the Swedish Dementia Quality Registry. Dement Geriatr Cogn Disord. 2012;33:90-5. https://doi.org/10.1159/ 000337038.

179. Rosen C, Farahmand B, Skillback T, Nagga K, Mattsson N, Kilander L, et al. Benchmarking biomarker-based criteria for Alzheimer's disease: data from the Swedish Dementia Registry. SveDem. Alzheimers Dement. 2015;11:1470-9. https://doi.org/ 10.1016/j.jalz.2015.04.007.

180. Hort J, Bartos A, Pirttila T, Scheltens P. Use of cerebrospinal fluid biomarkers in diagnosis of dementia across Europe. Eur J Neurol. 2010;17:90-6. https://doi.org/10.1111/j.1468-1331.2009.02753. $\mathrm{x}$.

181. Alcolea D, Martinez-Lage P, Izagirre A, Clerigue M, CarmonaIragui M, Alvarez RM, et al. Feasibility of lumbar puncture in the study of cerebrospinal fluid biomarkers for Alzheimer's disease: a multicenter study in Spain. J Alzheimers Dis. 2014;39:719-26. https://doi.org/10.3233/JAD-131334.

182. Thakur KT, Mateyo K, Hachaambwa L, Kayamba V, Mallewa M, Mallewa J, et al. Lumbar puncture refusal in sub-Saharan Africa: A call for further understanding and intervention. Neurology. 2015;84:1988-90. https://doi.org/10.1212/WNL. 0000000000001561 .

183. Magin P, Juratowitch L, Dunbabin J, McElduff P, Goode S, Tapley A, et al. Attitudes to Alzheimer's disease testing of Australian general practice patients: a cross-sectional questionnaire-based study. Int J Geriatr Psychiatry. 2016;31:361-6. https://doi.org/10.1002/gps.4335.

184. Evans RW, Armon C, Frohman EM, Goodin DS. Assessment: prevention of post-lumbar puncture headaches: report of the therapeutics and technology assessment subcommittee of the american academy of neurology. Neurology. 2000;55:909-14. https://doi. org/10.1212/wnl.55.7.909.

185. Duits FH, Martinez-Lage P, Paquet C, Engelborghs S, Lleo A, Hausner L, et al. Performance and complications of lumbar puncture in memory clinics: Results of the multicenter lumbar puncture feasibility study. Alzheimers Dement. 2016;12:154-63. https:// doi.org/10.1016/j.jalz.2015.08.003.
186. Peskind ER, Riekse R, Quinn JF, Kaye J, Clark CM, Farlow MR, et al. Safety and acceptability of the research lumbar puncture. Alzheimer Dis Assoc Disord. 2005;19:220-5. https://doi.org/10. 1097/01.wad.0000194014.43575.fd.

187. Menendez-Gonzalez M. Routine lumbar puncture for the early diagnosis of Alzheimer's disease. Is it safe? Front Aging Neurosci. 2014;6:65. https://doi.org/10.3389/fnagi.2014.00065.

188. Handels RL, Joore MA, Tran-Duy A, Wimo A, Wolfs CA, Verhey FR, et al. Early cost-utility analysis of general and cerebrospinal fluid-specific Alzheimer's disease biomarkers for hypothetical disease-modifying treatment decision in mild cognitive impairment. Alzheimers Dement. 2015;11:896-905. https://doi. org/10.1016/j.jalz.2015.02.009.

189. Valcarcel-Nazco C, Perestelo-Perez L, Molinuevo JL, Mar J, Castilla I, Serrano-Aguilar P. Cost-effectiveness of the use of biomarkers in cerebrospinal fluid for Alzheimer's disease. J Alzheimers Dis. 2014;42:777-88. https://doi.org/10.3233/JAD132216.

190. Lee SA, Sposato LA, Hachinski V, Cipriano LE. Costeffectiveness of cerebrospinal biomarkers for the diagnosis of Alzheimer's disease. Alzheimers Res Ther. 2017;9:18. https:// doi.org/10.1186/s13195-017-0243-0.

191. Bruandet A, Richard F, Bombois S, Maurage CA, Deramecourt V, Lebert F, et al. Alzheimer disease with cerebrovascular disease and vascular dementia: clinical features and course compared with Alzheimer disease. J Neurol Neurosurg Psychiatry. 2009;80:1339. https://doi.org/10.1136/jnnp.2007.137851.

192. Struyfs H, Molinuevo JL, Martin JJ, De Deyn PP, Engelborghs S. Validation of the AD-CSF-index in autopsy-confirmed Alzheimer's disease patients and healthy controls. J Alzheimers Dis. 2014;41:903-9. https://doi.org/10.3233/JAD-131085.

193. Seeburger JL, Holder DJ, Combrinck M, Joachim C, Laterza O, Tanen M, et al. Cerebrospinal fluid biomarkers distinguish postmortem-confirmed Alzheimer's disease from other dementias and healthy controls in the OPTIMA cohort. J Alzheimers Dis. 2015;44:525-39. https://doi.org/10.3233/JAD-141725.

194. Pottiez G, Yang L, Stewart T, Song N, Aro P, Galasko DR, et al. Mass-Spectrometry-Based Method To Quantify in Parallel Tau and Amyloid beta 1-42 in CSF for the Diagnosis of Alzheimer's Disease. J Proteome Res. 2017;16:1228-38. https://doi.org/10. 1021/acs.jproteome.6b00829.

195. Andreasson U, Kuhlmann J, Pannee J, Umek RM, Stoops E, Vanderstichele $\mathrm{H}$, et al. Commutability of the certified reference materials for the standardization of beta-amyloid 1-42 assay in human cerebrospinal fluid: lessons for tau and beta-amyloid 140 measurements. Clin Chem Lab Med. 2018;56:2058-66. https://doi.org/10.1515/cclm-2018-0147.

196. Kuhlmann J, Andreasson U, Pannee J, Bjerke M, Portelius E, Leinenbach A, et al. CSF Abeta1-42 - an excellent but complicated Alzheimer's biomarker - a route to standardisation. Clin Chim Acta. 2017;467:27-33. https://doi.org/10.1016/j.cca.2016.05.014.

197. Molinuevo JL, Blennow K, Dubois B, Engelborghs S, Lewczuk P, Perret-Liaudet A, et al. The clinical use of cerebrospinal fluid biomarker testing for Alzheimer's disease diagnosis: a consensus paper from the Alzheimer's Biomarkers Standardization Initiative. Alzheimers Dement. 2014;10:808-17. https://doi.org/10.1016/j. jalz.2014.03.003.

198. Herukka SK, Simonsen AH, Andreasen N, Baldeiras I, Bjerke M, Blennow K, et al. Recommendations for cerebrospinal fluid Alzheimer's disease biomarkers in the diagnostic evaluation of mild cognitive impairment. Alzheimers Dement. 2017;13:28595. https://doi.org/10.1016/j.jalz.2016.09.009.

199. Vogelgsang J, Wedekind D, Bouter C, Klafki HW, Wiltfang J. Reproducibility of Alzheimer's disease cerebrospinal fluidbiomarker measurements under clinical routine conditions. J 
Alzheimers Dis. 2018;62:203-12. https://doi.org/10.3233/JAD170793.

200. Wiltfang J, Esselmann H, Bibl M, Hull M, Hampel H, Kessler H, et al. Amyloid beta peptide ratio $42 / 40$ but not A beta 42 correlates with phospho-Tau in patients with low- and high-CSF A beta 40 load. J Neurochem. 2007;101:1053-9. https://doi.org/10.1111/j. 1471-4159.2006.04404.x.

201. Lewczuk P, Lelental N, Spitzer P, Maler JM, Kornhuber J. Amyloid-beta $42 / 40$ cerebrospinal fluid concentration ratio in the diagnostics of Alzheimer's disease: validation of two novel assays. J Alzheimers Dis. 2015;43:183-91. https://doi.org/10. 3233/JAD-140771.

202. Lucey BP, Fagan AM, Holtzman DM, Morris JC, Bateman RJ. Diurnal oscillation of CSF Abeta and other AD biomarkers. Mol Neurodegener. 2017;12:36. https://doi.org/10.1186/s13024-0170161-4.

203. Sato C, Barthelemy NR, Mawuenyega KG, Patterson BW, Gordon BA, Jockel-Balsarotti J, et al. Tau kinetics in neurons and the human central nervous system. Neuron. 2018;97:1284 98 e7. https://doi.org/10.1016/j.neuron.2018.02.015.
204. van Maurik IS, Visser LN, Pel-Littel RE, van Buchem MM, Zwan MD, Kunneman M, et al. Development and usability of ADappt: web-based tool to support clinicians, patients, and caregivers in the diagnosis of mild cognitive impairment and Alzheimer disease. JMIR Form Res. 2019;3:e13417. https://doi.org/10.2196/13417.

205. Tsvetkova DZ, Bergquist SH, Parker MW, Jarrett TL, Howell JC, Watts KD, et al. Fear and uncertainty do not influence reported willingness to undergo lumbar punctures in a U.S. multi-cultural cohort. Front Aging Neurosci. 2017;9:22. https://doi.org/10.3389/ fnagi.2017.00022.

206. Kroll H, Duszak R Jr, Nsiah E, Hughes DR, Sumer S, Wintermark $\mathrm{M}$. Trends in lumbar puncture over 2 decades: a dramatic shift to radiology. AJR Am J Roentgenol. 2015;204:15-9. https://doi.org/ 10.2214/AJR.14.12622.

207. O'Connor P, Lee L. Access to multiple sclerosis diagnosis for Canadian neurologists. Can J Neurol Sci. 1999;26:115-8.

Publisher's note Springer Nature remains neutral with regard to jurisdictional claims in published maps and institutional affiliations.

\section{Affiliations}

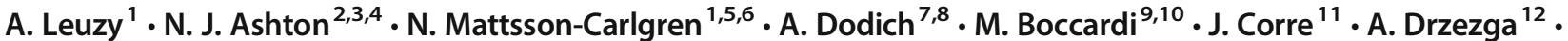 A. Nordberg ${ }^{13,14} \cdot$ R. Ossenkoppele ${ }^{1,15} \cdot$ H. Zetterberg ${ }^{2,16,17,18} \cdot K^{\text {K. Blennow }}{ }^{2,16} \cdot$ G. B. Frisoni ${ }^{9,19} \cdot$ V. Garibotto ${ }^{7}$. O. Hansson ${ }^{1,20}$}

1 Clinical Memory Research Unit, Department of Clinical Sciences, Lund University, SE-205 02 Malmö, Sweden

2 Department of Psychiatry and Neurochemistry, The Sahlgrenska Academy, University of Gothenburg, Mölndal, Sweden

3 Department of Old Age Psychiatry, Institute of Psychiatry, Psychology \& Neuroscience, King's College London, London, UK

4 Wallenberg Centre for Molecular and Translational Medicine, University of Gothenburg, Gothenburg, Sweden

5 Department of Neurology, Skåne University Hospital, Lund, Sweden

6 Wallenberg Centre for Molecular Medicine, Lund University, Lund, Sweden

7 NIMTlab - Neuroimaging and Innovative Molecular Tracers Laboratory, University of Geneva, Geneva, Switzerland

8 Center for Neurocognitive Rehabilitation (CeRiN), CIMeC, University of Trento, Trento, Italy

9 German Center for Neurodegenerative Diseases (DZNE), Rostock, Germany

10 LANVIE - Laboratory of Neuroimaging of Aging, University of Geneva, Geneva, Switzerland
11 Centre National de la Recherche Scientifique, Montpellier, France

12 Medical Faculty, University Hospital of Cologne, Cologne, Germany

13 Division of Clinical Geriatrics, Center for Alzheimer Research, Department of Neurobiology, Care Sciences and Society, Karolinska Institutet, Stockholm, Sweden

14 Theme Aging, Karolinska University Hospital, Stockholm, Sweden

15 Alzheimer Center Amsterdam, Department of Neurology, Amsterdam Neuroscience, Vrije Universiteit Amsterdam, Amsterdam UMC, Amsterdam, The Netherlands

16 Clinical Neurochemistry Laboratory, Sahlgrenska University Hospital, Gothenburg, Sweden

17 Department of Neurodegenerative Disease, UCL Queen Square Institute of Neurology, London, UK

18 UK Dementia Research Institute, UCL, London, UK

19 Memory Clinic, University Hospital, Geneva, Switzerland

20 Memory Clinic, Skåne University Hospital, SE-205 02 Malmö, Sweden 